Annales Geophysicae (2001) 19: 435-457 (C) European Geophysical Society 2001

\title{
Results of an interactively coupled atmospheric chemistry - general circulation model: Comparison with observations
}

\author{
R. Hein ${ }^{1}$, M. Dameris ${ }^{1}$, C. Schnadt ${ }^{1}$, C. Land ${ }^{1, *}$, V. Grewe ${ }^{1}$, I. Köhler ${ }^{1}$, M. Ponater ${ }^{1}$, R. Sausen ${ }^{1}$, B. Steil ${ }^{2}$, J. \\ Landgraf $^{2, * *}$, and C. Brühl ${ }^{2}$ \\ ${ }^{1}$ Institut für Physik der Atmosphäre, Deutsches Zentrum für Luft- und Raumfahrt e.V. (DLR), Oberpfaffenhofen, Wessling, \\ Germany \\ ${ }^{2}$ Abteilung Chemie der Atmosphäre, Max-Planck-Institut für Chemie, Mainz, Germany \\ *Now at Max-Planck-Institut für Meteorologie, Hamburg, Germany \\ ** Now at Space Research Organization Netherlands (SRON), Utrecht, The Netherlands
}

Received: 22 June 2000 - Revised: 8 November 2000 - Accepted: 29 November 2000

\begin{abstract}
The coupled climate-chemistry model ECHAM4.L39(DLR)/CHEM is presented which enables a simultaneous treatment of meteorology and atmospheric chemistry and their feedbacks. This is the first model which interactively combines a general circulation model with a chemical model, employing most of the important reactions and species necessary to describe the stratospheric and upper tropospheric ozone chemistry, and which is computationally fast enough to allow long-term integrations with currently available computer resources. This is possible as the model time-step used for the chemistry can be chosen as large as the integration time-step for the dynamics. Vertically the atmosphere is discretized by 39 levels from the surface up to the top layer which is centered at $10 \mathrm{hPa}$, with a relatively high vertical resolution of approximately $700 \mathrm{~m}$ near the extra-tropical tropopause. We present the results of a control simulation representing recent conditions (1990) and compare it to available observations. The focus is on investigations of stratospheric dynamics and chemistry relevant to describe the stratospheric ozone layer.

ECHAM4.L39(DLR)/CHEM reproduces main features of stratospheric dynamics in the arctic vortex region, including stratospheric warming events. This constitutes a major improvement compared to earlier model versions. However, apparent shortcomings in antarctic circulation and temperatures persist. The seasonal and interannual variability of the ozone layer is simulated in accordance with observations. Activation and deactivation of chlorine in the polar stratospheric vortices and their inter-hemispheric differences are reproduced. Considering methane oxidation as part of the dynamic-chemistry feedback results in an improved representation of the spatial distribution of stratospheric water vapour concentrations.

The current model constitutes a powerful tool to investigate, for instance, the combined direct and indirect effects of anthropogenic trace gas emissions.
\end{abstract}

Key words. Atmospheric composition and structure (mid-

Correspondence to: M. Dameris (martin.dameris@dlr.de) dle atmosphere - composition and chemistry) - Meteorology and atmospheric dynamics (general circulation; middle atmosphere dynamics)

\section{Introduction}

Comprehensive numerical models describing different components of the atmospheric system are important tools for understanding the Earth's climate system and for assessing its future evolution by means of scenario simulations. In recent years, strong efforts have been made to improve the quality of such models. With increasing computer power, it has become possible to increase the complexity and spatial resolution of these models. In addition to the efforts to couple the atmosphere with ocean general circulation models (AGCMs and OGCMs, respectively), recent improvements of AGCMs include, for instance, a better representation of land surface processes.

There have also been efforts to incorporate changes in the chemical composition of the atmosphere into AGCMs. Special attention is dedicated to a more appropriate representation of greenhouse gases (GHGs). Increasing abundances of many important GHGs, among them carbon dioxide, methane, nitrous oxide, and chlorofluorocarbons, have been observed during the last decades (IPCC, 1996). They lead to a warming of the lower troposphere and to a cooling of the stratosphere, generally referred to as additional greenhouse effect (e.g. Austin and Butchart, 1994; Mitchell et al., 1990; Rind et al., 1998; Roeckner et al., 1999; Santer et al., 1996; Shindell et al., 1998a). Chemically induced temperature changes also alter other meteorological features, such as circulation patterns, storm tracks, and precipitation. In turn, transport, temperature, and radiation influence the abundance of chemically active trace gases, such as nitrogen oxides, ozone, carbon monoxide, and methane, e.g. due to the temperature dependence of photochemical reaction rates. Hence, atmospheric chemistry and dynamics constitute an interactively coupled system. An adequate 
treatment of ozone in AGCMs is particularly important to improve the agreement of simulated and observed temperature trends (Bengtsson et al., 1999; Santer et al., 1999). However, in most AGCMs, prescribed GHG concentrations including ozone are applied, thus neglecting the interaction of chemistry and climate. Moreover, some AGCMs cannot treat different GHGs separately. They simply rely on the concept of equivalent $\mathrm{CO}_{2}$ concentrations. This concept may be adequate to describe the influence of changing abundances of long-lived GHGs. However, it is neither suitable to assess the impact of short-lived radiatively active gases nor can one account for the effects arising from interactions of dynamic and chemical changes.

Only recently, a very limited number of papers discussing long-term integrations performed with interactively coupled chemistry-AGCMs have been published (e.g. Shindell et al., 1998b; Austin et al., 2000). The development of interactively coupled chemistry-AGCMs like the ECHAM4.L39(DLR)/ CHEM model (hereafter referred to as E39/C) presented in this paper constitutes an important milestone to improve our understanding of the dynamic-chemistry feedback mechanisms in the atmosphere.

In this paper, we present the first interactively coupled chemistry-climate model, which allows one to study chemistry-climate feedback mechanisms in decadal integrations, and in which the physical, chemical, and transport processes are calculated simultaneously at each time-step (30 minutes). This means great progress with respect to similar model systems, which use either simplified chemistry parameterizations, or with which shorter simulations of specific episodes are carried out, due to a necessary short time-step in chemistry. In discussing the model results, we focus on the features relevant for describing the development of the stratospheric ozone layer. Special emphasis is given to the dynamics of the stratospheric polar vortices and the chemical composition of the lower stratosphere, particularly the abundances of ozone, water vapour, and chlorine oxides. Climatological model results are validated with available long-term observations. We employ a particular version of the AGCM ECHAM4 (Roeckner et al., 1996) for the dynamic component.

The applied chemistry module is an updated version of the chemistry module CHEM which was originally used in conjunction with the former version of the ECHAM model. This previous model, ECHAM3/CHEM (Steil et al., 1998), was employed in several studies to assess the behaviour of the ozone layer (Grewe and Dameris, 1997; Grewe et al., 1998), to assess its possible future development (Dameris et al., 1998a), and to investigate the chemical effects of aircraft emissions (Dameris et al., 1998b; Grewe et al., 1999). A major shortcoming of the ECHAM3/CHEM model system was the fact that the impact of changes in concentrations of chemical species to the radiation could not adequately be represented, as the radiation scheme of ECHAM3 (Roeckner et al., 1992) was not designed for this purpose.

Since AGCMs have been predominantly used as tools to reproduce realistic climate patterns, development and valida- tion of AGCMs have been usually focussed on a realistic representation of tropospheric meteorological processes. Stratospheric dynamics have been often viewed to be of secondary interest. Therefore, the latter has only been crudely represented in many AGCMs. To give one example, ECHAM3/ CHEM tends to simulate too stable stratospheric polar vortices in winter and spring, i.e. too strong westerly winds and too low temperatures, particularly in the northern hemisphere (Grewe et al., 1998). Systematic errors of this kind have often been attributed to a low model top. However, it is important to note that such features may also be found in a considerable number of Middle Atmosphere-GCMs (MA-GCMs), extending from the Earth's surface up to mesospheric height levels (Pawson et al., 2000).

Some shortcomings found in the ECHAM3/CHEM results concerning stratospheric dynamics and chemistry may be attributed not only to its top layer at $10 \mathrm{hPa}$, but also to its low vertical resolution, particularly in the lower stratosphere (Steil et al., 1998). To overcome these problems, two different upgraded versions of the coupled model have been developed: MA-ECHAM4/CHEM and E39/C. The first version is based on the MA-ECHAM4 model (Manzini and McFarlane, 1998), which extends to a top level at $0.01 \mathrm{hPa}$ using 39 levels to eliminate problems arising from having the top level at $10 \mathrm{hPa}$. However, in MA-ECHAM4, the vertical resolution in the upper troposphere and in the lower stratosphere is not substantially enhanced relative to the ECHAM4 standard version.

By chance, the second version, E39/C, which is introduced in this paper, also uses 39 levels. In contrast to the MAECHAM4, additional levels are mainly added in the upper troposphere and lower stratosphere in order to reduce the problems arising from the relatively coarse vertical resolution of the standard version with 19 vertical levels (L19). In $\mathrm{E} 39 / \mathrm{C}$, the top model layer remains at $10 \mathrm{hPa}$. In the long-term, a model with increased vertical resolution near the tropopause and an enhanced upper boundary is certainly desirable. However, long-term integrations with such a model are currently beyond our practical limits of computational resources. The inclusion of the middle atmosphere requires a smaller dynamic time-step (e.g. 15 minutes in MA-ECHAM4) and a larger number of tracers. Combined with an increased vertical resolution as adopted in E39/C, decadal integrations with such a model would exceed the necessary computer power (CPU-time and mass storage) significantly, e.g. a simulation of a 24-year period with E39/C currently requires approximately 8000 hours CPU-time on a single CRAY-J90 processor and produces nearly 200 GBytes of data.

In Sect. 2, general features of the ECHAM4 model and details of the updated CHEM module are described. Section 3 is devoted to a presentation of results of a long-term integration with the interactively coupled E39/C model. Selected dynamic and chemical model features are compared to satellite and ozone sonde measurements. In Sect. 4, possible reasons for the merits and shortcomings of the model are discussed. The main conclusions are drawn in Sect. 5. 


\section{Model description}

The atmosphere general circulation model ECHAM4.L39 (DLR) (hereafter referred to as E39) (Land et al., 1999) is based on the standard version of the ECHAM4 model (Roeckner et al., 1996). Whereas the standard version of ECHAM4 uses 19 vertical layers, the number of layers has been increased to 39 in E39, with the highest gain of vertical resolution in the upper troposphere and lower stratosphere, while the top model level remains centered at $10 \mathrm{hPa}$. The vertical resolution in the extra-tropical tropopause region has been enhanced from approximately $2 \mathrm{~km}$ to $700 \mathrm{~m}$. Among other effects, the increased number of vertical levels leads to a lifting of the so-called "sponge" layer of the model, i.e. those uppermost layers, in which horizontal diffusion is gradually enhanced to prevent spurious wave reflection at the upper model boundary. Thus, the domain in which these numerical requirements yield a substantially suppressed model variability (probably the two uppermost layers) is restricted to the region above approximately $25 \mathrm{hPa}$. In this study, the model is applied with a horizontal resolution of T30, i.e. dynamic processes have a horizontally isotropic resolution of $6^{\circ}$ (nearly $670 \mathrm{~km}$ ). The corresponding Gaussian transform latitude-longitude grid, on which model physics, chemistry, and tracer transport are calculated with a time-step of $30 \mathrm{~min}$ utes each, has a grid size of approximately $3.75^{\circ} \times 3.75^{\circ}$.

ECHAM4 is based on the primitive equations with the prognostic variables vorticity, divergence, temperature, logarithm of surface pressure, and the mixing ratios of water vapour and cloud water and, optionally, tracer mixing ratios. Water vapour, cloud water, and tracers are advected by the semi-Lagrangian scheme of Williamson and Rasch (1994), while spectral Eulerian advection is applied to the other prognostic variables. Parameterization schemes for radiation (Fouquart and Bonnel, 1980; Morcrette, 1991; van Dorland et al., 1997), convection (Tiedtke, 1989), large-scale cloud formation (Roeckner, 1995), land surface processes, orographic gravity wave drag (Miller et al., 1989), and vertical turbulent diffusion (Louis, 1979; Brinkop and Roeckner, 1995) are employed. The model version described here (E39) includes an improved parameterization of water vapour pressure over ice (Sonntag, 1994). It yields more realistic, i.e. lower, stratospheric water vapour mixing ratios, since water vapour saturation pressure over ice in the ECHAM4 standard model is overestimated at very low temperatures (below $200 \mathrm{~K}$, which can be found near the tropical tropopause or in the stratospheric polar vortices during winter) by 10 to 20 percent. E39 also includes a modified convection parameterization, which ensures non-negative tracer concentrations (Brinkop and Sausen, 1997).

Notable differences of the tropospheric E39 climatology compared to the standard L19 version are restricted to a few variables, such as cloud coverage and variability of temperature and winds on both daily and weekly time scales (Land et al., 1999). Climatic mean differences of other quantities are small. The transport characteristics of E39 are clearly superior to the standard L19 model, predominantly due to
Table 1. Transported chemical species and families

$\mathrm{CH}_{4}, \mathrm{~N}_{2} \mathrm{O}, \mathrm{HCl}, \mathrm{H}_{2} \mathrm{O}_{2}, \mathrm{CO}, \mathrm{CH}_{3} \mathrm{O}_{2} \mathrm{H}, \mathrm{ClONO}_{2}, \mathrm{OX}, \mathrm{NOX}^{-\mathrm{ClO}_{\mathrm{x}}}$,
$\mathrm{HNO}_{3}$ + type I PSC (NAT: $\left.\mathrm{HNO}_{3} \cdot 3 \mathrm{H}_{2} \mathrm{O}\right), \mathrm{H}_{2} \mathrm{O}+$ type II PSC (water ice)
with
$\mathrm{ClO}_{\mathrm{x}}=\mathrm{Cl}+\mathrm{ClO}+\mathrm{ClOH}+2 \cdot \mathrm{Cl}_{2} \mathrm{O}_{2}+2 \cdot \mathrm{Cl}_{2}$
$\mathrm{NOX} \quad=\mathrm{N}+\mathrm{NO}+\mathrm{NO}_{2}+\mathrm{NO}_{3}+2 \cdot \mathrm{N}_{2} \mathrm{O}_{5}+\mathrm{HNO}_{4}$
$\mathrm{OX} \quad=\mathrm{O}_{3}+\mathrm{O}\left({ }^{3} \mathrm{P}\right)+\mathrm{O}\left({ }^{1} \mathrm{D}\right)$

a substantially reduced numerical diffusion of the semiLagrangian scheme (Rasch and Lawrence, 1998; Timmreck et al., 1999). Like practically all climate models worldwide, $\mathrm{E} 39 / \mathrm{C}$ is not able to generate the equatorial quasi-biennial oscillation (QBO) internally, which affects stratospheric dynamics not only in the tropics but also at mid- and high latitudes.

The chemistry module CHEM (Steil et al., 1998) contains the most relevant chemical processes required to describe stratospheric ozone chemistry, as well as tropospheric background $\mathrm{NO}_{\mathrm{x}}-\mathrm{HO}_{\mathrm{x}}-\mathrm{CH}_{4}-\mathrm{CO}-\mathrm{O}_{3}$ chemistry. It includes heterogeneous reactions on polar stratospheric clouds (PSCs) of type I (nitric acid trihydrate, NAT) and of type II (ice), and on sulfate aerosol. The classical theory of Hanson and Mauersberger (1988) is used to determine when PSCs are thermodynamically possible, based on the simulated temperature and the mixing ratios of $\mathrm{HNO}_{3}$ and $\mathrm{H}_{2} \mathrm{O} .107$ gas phase reactions and 37 chemical species are taken into account. Applying the family concept, only 12 individual species or families have to be transported (Table 1). CHEM is very economical concerning its numeric resources, since the chemical integration time-step can be chosen as large as the integration time-step of the dynamic model (30 minutes). This enables several long-term (decadal) integrations with the coupled chemistryclimate model E39/C on currently available medium performance computers.

Dry deposition of 10 species and wet deposition of 3 soluble species is included, following Roelofs and Lelieveld (1995) and Dentener and Crutzen (1993). Monthly mean concentrations of chlorofluorocarbons (CFCs) depending on latitude and altitude are prescribed, at $10 \mathrm{hPa} \mathrm{ClX}$ (= $\left.\mathrm{HCl}+\mathrm{ClONO}_{2}+\mathrm{ClO}_{\mathrm{x}}\right)$ and $\mathrm{NO}_{\mathrm{y}}\left(=\mathrm{NOX}+\mathrm{HNO}_{3}\right)$ are given as upper boundary conditions based on monthly averaged results derived with the 2-D model of Brühl and Crutzen (1993). The mean total inorganic chlorine mixing ratio $\left(\mathrm{Cl}_{\mathrm{y}}\right)$ in the model stratosphere amounts to $3.3 \mathrm{ppbv}$, which is in agreement with observed values around the year 1990 (WMO, 1999). Presently, CHEM does not include bromine chemistry. This should have an influence on calculated ozone depletion rates, particularly in the northern hemisphere, where the impact of bromine on ozone depletion is assumed to be larger than in the southern hemisphere, since ozone is only partly destroyed by chlorine. This must be taken into account when analyzing the model results.

In addition to the work of Steil et al. (1998), wet deposition of $\mathrm{H}_{2} \mathrm{O}_{2}$ is taken into account. Reaction rates have been up- 
dated (DeMore et al., 1994). An efficient calculation of photolysis rates has been included (Landgraf and Crutzen, 1998). Nitrogen oxide $\left(\mathrm{NO}_{\mathrm{x}}=\mathrm{NO}+\mathrm{NO}_{2}\right)$ emissions from lightning (Table 2) are calculated on-line, based on a parameterization using model-calculated cloud top heights (Price and Rind, 1992, 1994). The dependence of flash frequency on model grid size and the amount of $\mathrm{NO}_{\mathrm{x}}$ emitted per flash are adjusted to yield global $\mathrm{NO}_{\mathrm{x}}$ emissions from lightning of approximately $5 \mathrm{Tg}(\mathrm{N}) / \mathrm{yr}$ as a long-term mean in a present day climate. Although published estimates of global annual $\mathrm{NO}_{\mathrm{x}}$ production from lightning range from as low as 2 to as high as $100 \mathrm{Tg}(\mathrm{N}) / \mathrm{yr}$ (Logan, 1983; Franzblau and Popp, 1989), recent estimates seem to converge around 4 to $5 \mathrm{Tg}(\mathrm{N}) / \mathrm{yr}$ (e.g. Lee et al., 1997; Huntrieser et al., 1998). Methane and carbon monoxide mixing ratios at the surface have been prescribed using the results of Hein et al. (1997), and more recent estimates of $\mathrm{NO}_{\mathrm{x}}$ surface and aircraft emissions have been applied. The cloud parameterization scheme is adjusted to stratospheric conditions to prevent an excessive cloud formation in the polar lower stratosphere and a subsequent extreme dehydration of the polar lower stratosphere.

Usually, prescribed climatological mixing ratios of GHGs have been applied in AGCM calculations without chemistry. In addition many previous AGCMs including chemistry, for example ECHAM3/CHEM, applied prescribed GHG concentrations for the calculations of heating rates. They only employed a mode in which the chemistry module uses meteorological variables of the model, but the dynamic and radiative parts of the model are not influenced by the chemical calculations. Such GCM configurations resemble chemical transport models (CTMs). In contrast, the present E39/C model includes an on-line feedback of chemistry to the dynamic and radiative parts (Fig. 1, bold arrow). At each time-step, the simulated concentrations of the radiatively active gases ozone $\left(\mathrm{O}_{3}\right)$, methane $\left(\mathrm{CH}_{4}\right)$, nitrous oxide $\left(\mathrm{N}_{2} \mathrm{O}\right)$, chlorofluorocarbons (CFCs), and water vapour $\left(\mathrm{H}_{2} \mathrm{O}\right)$ are used in the radiative calculations. Thus, changes in the abundance of these gases, due to chemical processes, interactively influence heating rates and, consequently, dynamic model variables. Since $\mathrm{CH}_{4}, \mathrm{~N}_{2} \mathrm{O}$, and CFCs are long-lived GHGs with a nearly uniform mixing ratio, at least in the troposphere, we expect their interactive dynamic-chemistry feedback only to be of minor importance on an interannual time scale. The interactive coupling of the concentrations of the short-lived GHGs $\mathrm{O}_{3}$ and $\mathrm{H}_{2} \mathrm{O}$ is most important, since they show a relatively high variability, which cannot be approximated adequately by prescribed background conditions. Methane oxidation is quite an important water vapour source in the stratosphere, where prevailing $\mathrm{H}_{2} \mathrm{O}$ concentrations are low and physical water vapour sources and sinks are not as dominant as in the troposphere. Although chemical water vapour production by methane oxidation can also be captured in purely meteorological models by an adequate parameterization (e.g. Simmons et al., 1999), its inclusion in an interactive chemistry module is certainly much more flexible and conceptually satisfactory.

The present paper focuses on a quasi-equilibrium refer- ence simulation representing the 1990 time slice, i.e. with a carbon dioxide $\left(\mathrm{CO}_{2}\right)$ concentration of $353 \mathrm{ppmv}$, sea surface temperatures prescribed to the average of the years 19791994 (Gates, 1992), and chemical boundary conditions representative for the beginning 1990s (Table 3). After a spin-up period of 4 years, the model is integrated over 20 annual cycles in quasi-equilibrium mode. Results of these 20 years (model years 5 to 24 ) are analyzed and presented in the following section.

\section{Model results and comparison with observations}

This section is devoted to the presentation and validation of model results relevant for describing the development of the stratospheric ozone layer. Since dynamic and chemical processes are critical for the distribution of stratospheric ozone, particularly for ozone loss in polar winter and spring, we look at both chemical and dynamic variables. Dynamic investigations focus on zonal mean temperatures and zonal winds (Sect. 3.1). Stratospheric methane is taken as an indicator of vertical motion inside the polar vortices (Sect. 3.2). With respect to chemistry, the main interest focuses on ozone (Sect. 3.3). Water vapour concentrations are also discussed (Sect. 3.4). Finally, we look at the representation of chlorine activation and deactivation (Sect. 3.5).

It must be kept in mind that the observed data employed for model evaluation also have some shortcomings, indicated by differences between the analyses themselves. Error bars of the measurements are in many cases insufficiently documented. For the current investigation, it is important to use long-term data sets to have a reliable basis for model evaluation. Such data sets are few and we are aware that the conclusions regarding the quality of the model results may be subject to change if other data sets could be or would be used.

\subsection{Lower stratosphere dynamics}

In this subsection, we investigate the dynamics of the E39/C model system in the lower stratosphere, especially in the northern hemisphere. Zonal and monthly means of the zonal model winds (Fig. 2) indicate that the position of the subtropical and polar wind jets are in reasonable agreement with European Center for Medium Range Weather Forecasts (ECMWF) re-analyses for the years 1979-1994 (e.g. Gates et al., 1999). Sub-tropical and polar night jets are clearly distinguishable, i.e. a transition zone with reduced wind speed is found in both hemispheres under solstice conditions. A more detailed comparison offers some differences with respect to observations. For example, in January, at higher latitudes in the southern (summer) hemisphere, the model does not reproduce easterly winds between 20 and $50 \mathrm{hPa}$; the northern polar night jet is a little bit too strong. In July, the polar vortex in winter is much stronger than indicated by climatological means of observations (approx. $10 \mathrm{~m} \mathrm{~s}^{-1}$ ). Pawson et al. (2000) discussed the results of 13 MA-GCMs regarding 
Table 2. Nitrogen Oxide emissions

\begin{tabular}{|c|c|c|c|}
\hline Source type & $\begin{array}{l}\text { Global source } \\
\text { magnitude } \\
(\mathrm{Tg}(\mathrm{N}) / \mathrm{yr})\end{array}$ & Major source area & Reference \\
\hline Industry & 22.6 & $\begin{array}{l}\text { industrial areas (predominantly eastern United States, } \\
\text { central Europe, and Japan) }\end{array}$ & Benkovitz et al. (1996) \\
\hline Soils & 5.5 & tropical land (except deserts) & Yienger and Levy (1995) \\
\hline Biomass burning & 5 & land, between $25^{\circ} \mathrm{N}$ and $25^{\circ} \mathrm{S}$ (in dry season) & Hao et al. (1990) \\
\hline Lightning & $5.4 \pm 0.1$ & $\begin{array}{l}\text { middle and upper tropical troposphere (linked to con- } \\
\text { vective activity) }\end{array}$ & Price and Rind (1994) \\
\hline Aircraft & 0.6 & $\begin{array}{l}\text { predominantly over Europe, United States, and the } \\
\text { North Atlantic Flight Corridor }\end{array}$ & $\begin{array}{l}\text { Schmitt and Brunner } \\
\text { (1997) }\end{array}$ \\
\hline
\end{tabular}

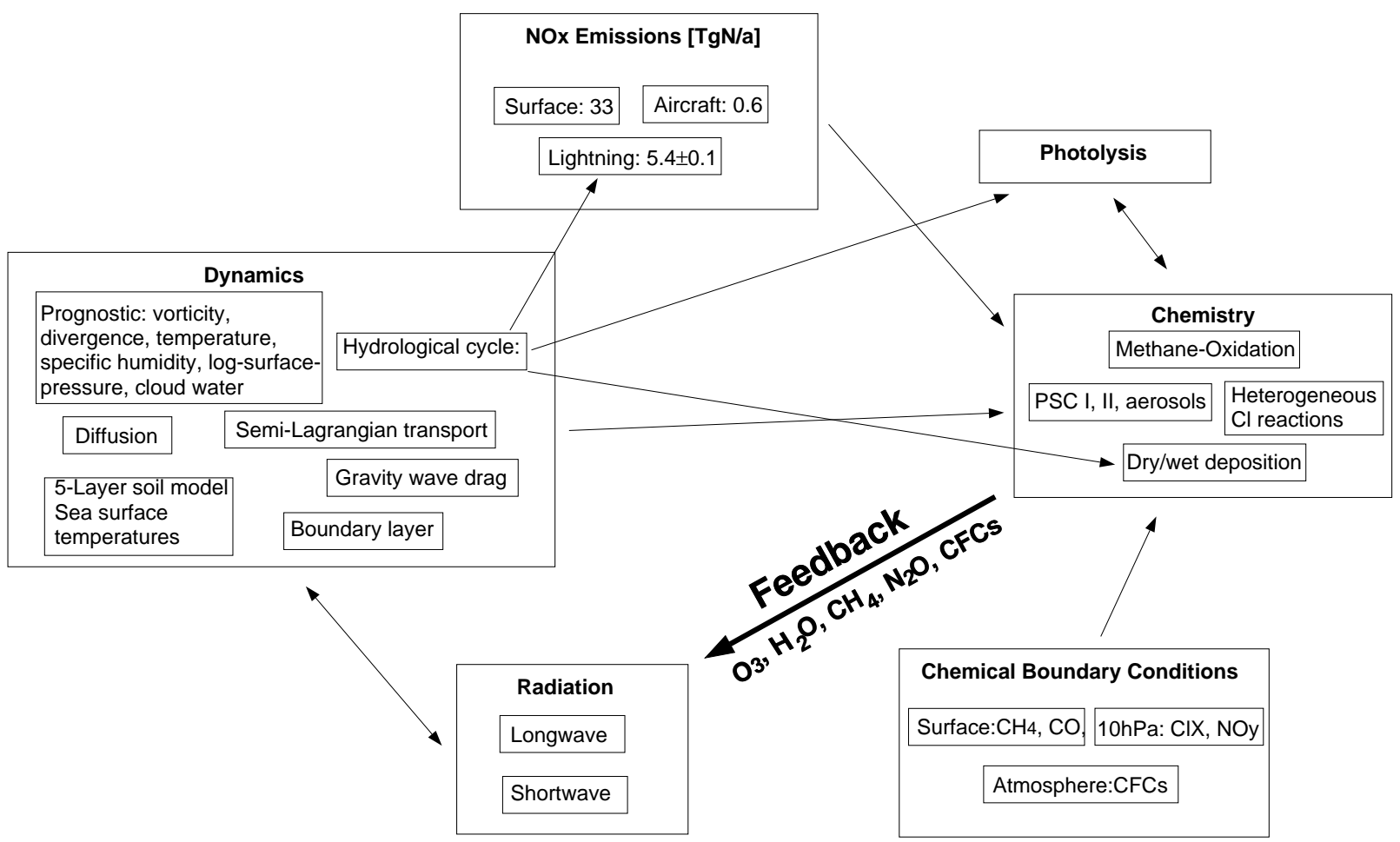

Fig. 1. Schematic overview of the processes involved in ECHAM4/CHEM, particularly the coupling between chemistry and climate. The feedback of chemistry to dynamics through its influence on radiation is highlighted (bold arrow).

climatological zonal mean wind fields for January and compared them to corresponding observations (Randel, 1992). The E39/C results fit into the range of results covered by the MA-GCMs. Some of the deficiencies mentioned above are also detected in some of the MA-GCMs, which indicates that the problems arising in E39/C are not exclusively related to its upper boundary centered at $10 \mathrm{hPa}$. The model E39/C, which does not generate the QBO internally, indicates permanent easterly winds in the equatorial lower stratosphere, which should enhance the dynamic variability, particularly in the northern winter hemisphere (Holton and Tan, 1982, Dameris and Ebel, 1990). To illustrate in more detail the capabilities and deficiencies of E39/C in simulating the polar vortex dynamics, we focus on annual cycles of zonal winds and temperatures at $30 \mathrm{hPa}$. Climatological mean annual cycles of zonal means of stratospheric zonal winds at $60^{\circ} \mathrm{N}$, $30 \mathrm{hPa}$, and of the temperatures at $80^{\circ} \mathrm{N}, 30 \mathrm{hPa}$ are presented in Fig. 3. Figure 4 shows the corresponding results for the southern hemisphere (winds at $60^{\circ} \mathrm{S}$ and temperatures at $80^{\circ} \mathrm{S}$ ). Our model results are displayed in the right panels of Figs. 3 and 4. For comparison, analyses of long-term observations (1978-1998) from the National Centers for Environmental Prediction (NCEP, data provided by P. Newman, E.R. Nash, and R.M. Nagatani; can be accessed 
Table 3. Boundary conditions for chemical species

\begin{tabular}{lll}
\hline Species & Boundary condition & Reference \\
\hline $\mathrm{CH}_{4}$ & $\begin{array}{l}\text { prescribed monthly mean surface mixing ratios } \\
\text { prescribed monthly and zonal mean surface mixing ratios, enhanced over land }\end{array}$ & $\begin{array}{l}\text { (Hein et al., 1997) } \\
\text { in agreement with (Hein et } \\
\text { al., 1997) }\end{array}$ \\
$\mathrm{NO}_{\mathrm{y}}$ & monthly and zonal mean mixing ratio at $10 \mathrm{hPa}$ prescribed from 2-D model & $\begin{array}{l}\text { Brühl and Crutzen (1993); } \\
\text { Grooß (1996) }\end{array}$ \\
$\mathrm{ClX}$ & monthly and zonal mean mixing ratio at 10 hPa prescribed from 2-D model & $\begin{array}{l}\text { Brühl and Crutzen (1993); } \\
\text { Grooß (1996) }\end{array}$ \\
$\mathrm{CFCs}$ & monthly and zonal mean mixing ratio prescribed from 2-D model & Brühl and Crutzen (1993); \\
& & Grooß (1996) \\
\hline
\end{tabular}

via "http://hyperion.gsfc.nasa.gov") are displayed in the left panels. Bold black lines in both figures represent climatological averages of 20 years. As a measure of the interannual variability, the shaded areas denote the minimum to maximum range of the data.

Obviously, the model is capable of reproducing a large part of the stratospheric dynamic variability in the northern hemisphere, and of covering the strong inter-hemispheric differences in the variability of lower stratosphere dynamics apparent in the observations. The annual cycles of simulated climatological temperatures and zonal winds in the northern hemisphere are in good agreement with the NCEP data. The winter minimum of the mean temperature is slightly lower in the model $(197 \mathrm{~K})$ than in the NCEP analyses $(200 \mathrm{~K})$. In summer, modeled maximum temperatures $(234 \mathrm{~K})$ are slightly higher than in the NCEP analyses (232 K). Consistent with the temperature difference, modeled mean zonal winds in winter are stronger than observed $\left(35 \mathrm{~m} \mathrm{~s}^{-1}\right.$ versus $30 \mathrm{~m} \mathrm{~s}^{-1}$ ). All of these differences are small compared to the interannual variability of the respective variables. Nevertheless, it must be kept in mind that such differences, although small, may affect chemistry. The apparent reversal of zonal winds in the NCEP analyses in summer is reproduced in the model. However, easterly wind speed in early July peaks at only $3 \mathrm{~m} \mathrm{~s}^{-1}$ (versus $7 \mathrm{~m} \mathrm{~s}^{-1}$ in the NCEP analyses). The modeled northern hemisphere interannual variability is clearly enhanced compared to former model versions, as will be discussed in more detail below. The present result constitutes a remarkable overall improvement relative to ECHAM3/CHEM results (Steil et al., 1998; Grewe et al., 1998).

The comparison of southern hemisphere model results with the NCEP analyses reveals somewhat larger differences. Most striking is a delay of approximately one month in the modeled warming in spring (Fig. 4). In comparison to ECHAM3/CHEM results (Steil et al., 1998), where the time shift was approximately 6 weeks, this is only a marginal improvement. The model is generally not able to simulate the observed wind reversal in summer at $60^{\circ} \mathrm{S}, 30 \mathrm{hPa}$ (see also Fig. 2a). The interannual variability (in terms of peakto-peak range) of southern hemisphere polar stratospheric temperatures is obviously underestimated. The minimum temperatures in winter at $80^{\circ} \mathrm{S}, 30 \mathrm{hPa}$ are significantly lower than in the NCEP data (approximately $10 \mathrm{~K}$ ). At $50 \mathrm{hPa}$, differences between model results and observations are smaller, but temperatures are still underestimated by approximately $5 \mathrm{~K}$ (not shown). This cold bias in the lower stratosphere is a prominent feature in most AGCMs, including a considerable number of MA-versions (Pawson et al., 2000). We like to note, however, that this result contrasts with former ECHAM versions, calculating several Kelvin temperatures too high at the $50 \mathrm{hPa}$ level. In ECHAM3/CHEM this temperature bias contributed perceptibly to an underestimation of chlorine activation and the size of the ozone hole. In contrast, the current model, with the cold bias at $50 \mathrm{hPa}$, yields a high chlorine activation, as discussed in Sect. 3.5.

The remarkable ability of E39/C to reproduce fairly well both the climatological mean dynamic conditions and the dynamic variability in the northern hemisphere lower stratosphere during winter and spring, is further demonstrated in Fig 5. Here, black bold lines represent the modeled climatological mean annual cycle of the zonal mean of the zonal wind at $60^{\circ} \mathrm{N}, 30 \mathrm{hPa}$ and of the temperature difference between North Pole and $60^{\circ} \mathrm{N}, 30 \mathrm{hPa}$, respectively. Both, wind and temperature are in general agreement with NCEP analyses, and with analyses performed at the Freie Universität Berlin (Naujokat et al. (1993), their Fig. 2), e.g. the strongest climatological temperature difference between the North Pole and $60^{\circ} \mathrm{N}$ is observed in early January $(-15 \mathrm{~K})$, and the model indicates a stronger temperature difference of $-20 \mathrm{~K}$ at that time. The climatological mean temperature difference is systematically overestimated in the model $(-3 \mathrm{~K}$ to $-10 \mathrm{~K}$ between December and March). The reversal of the temperature difference is calculated by E39/C in late March, only a few days later than indicated by the Berlin analysis.

Large deviations of individual model years from the climatological mean state are apparent, indicating a reasonably realistic interannual variability in the model. In Fig. 5, we display the following five examples to demonstrate that the model covers the large variety of dynamic conditions, which have been observed during the last 20 northern winters:

- a strong stratospheric warming in mid-January of model year 17 with westerly zonal mean winds at $60^{\circ} \mathrm{N}$ weak- 

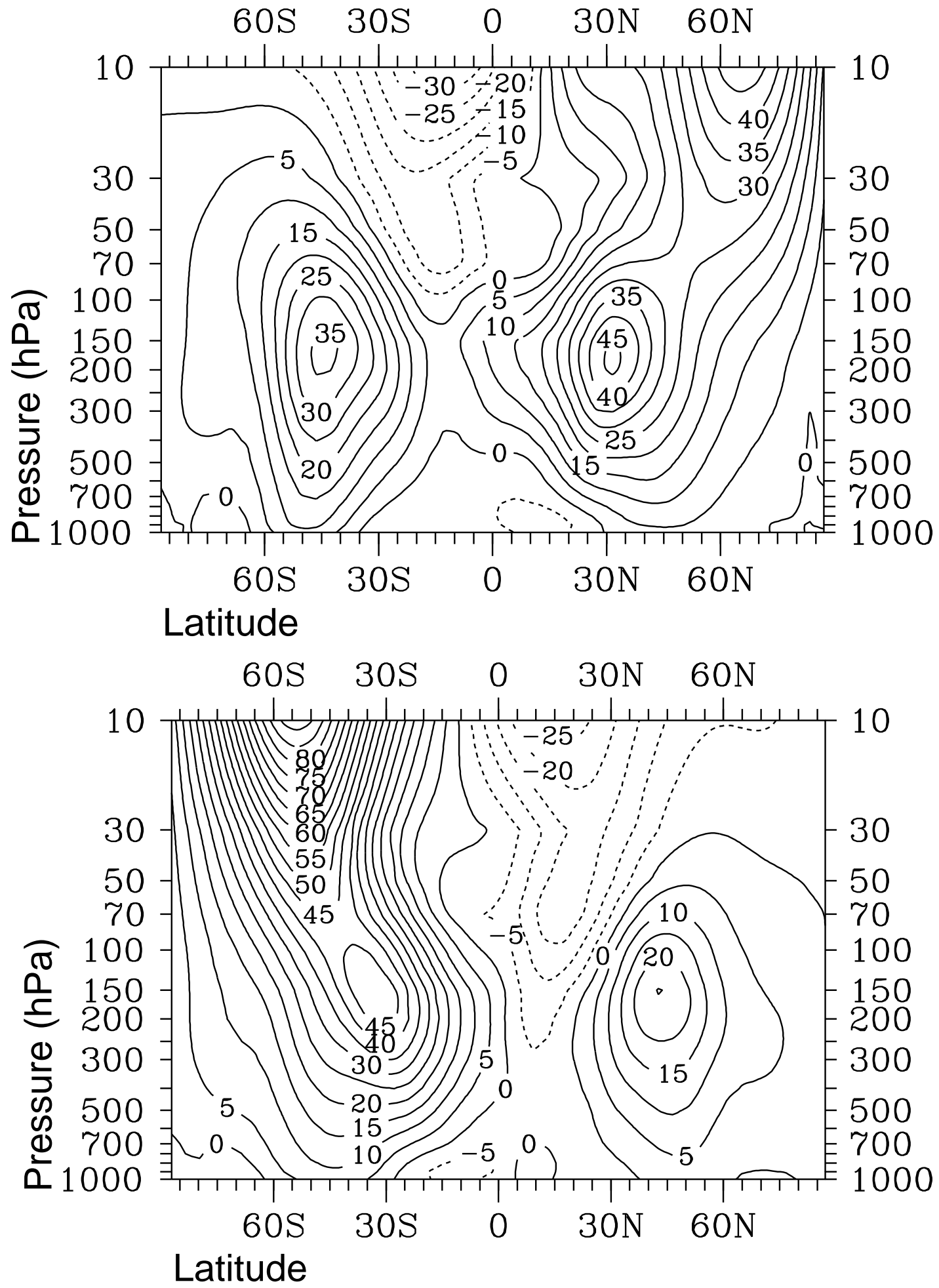

Fig. 2. Climatological zonal mean wind fields for January (top) and July (bottom), based on the 20-year model simulation.

ening to less than $10 \mathrm{~m} \mathrm{~s}^{-1}$ and a subsequent recovery of the polar vortex until mid-February (blue lines),

- minor warmings in February of the model years 10 and 12 (red and green lines),
- a weak, early (Canadian) warming at the end of December of model year 16 (blue lines),

- a major final warming end in March of model year 11 (yellow lines), and 

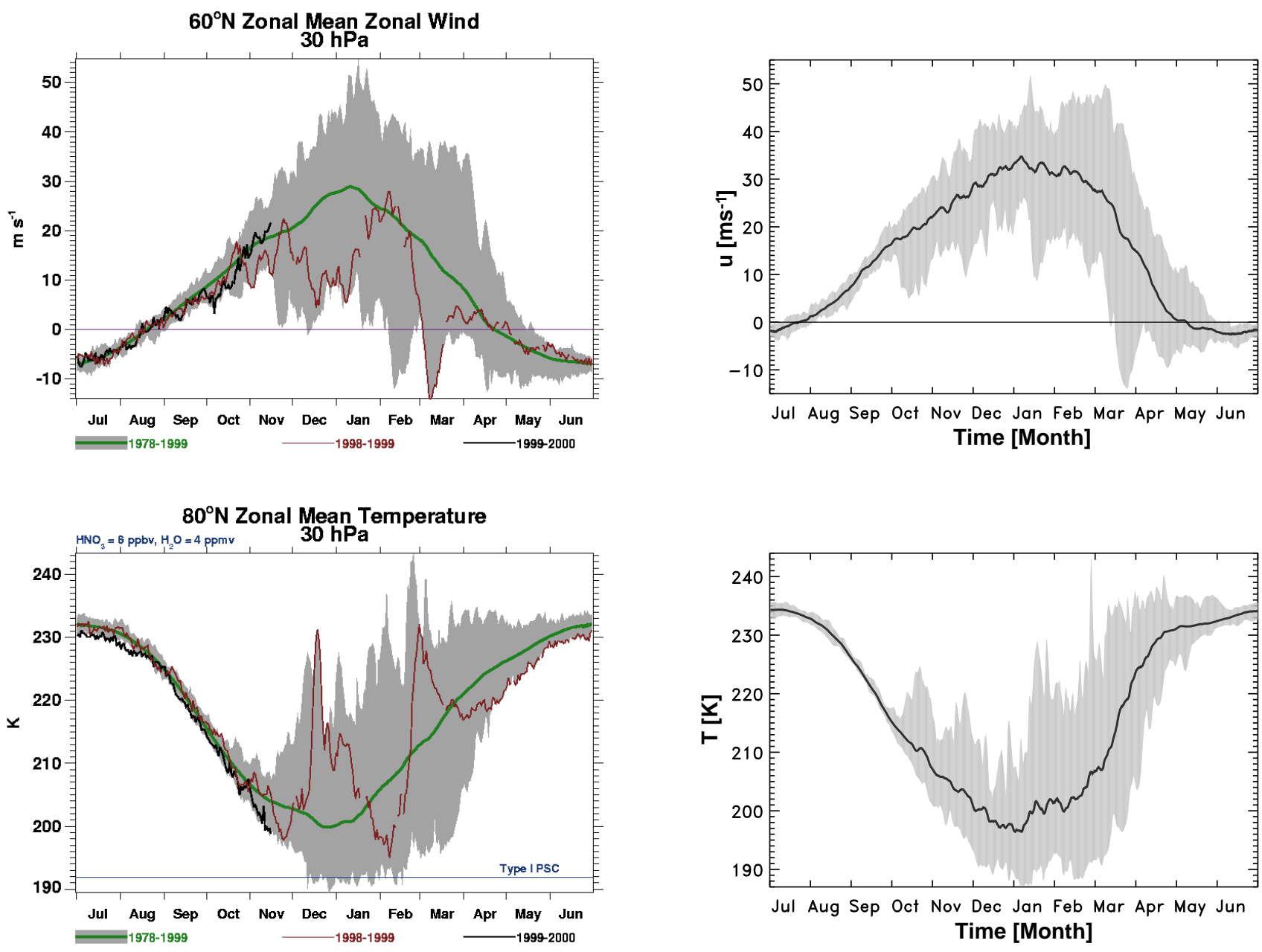

P. Newman (NASA), E. Nash (SM\&A), R. Nagatani (NCEP CPC)

Fig. 3. Analyzed observed (left) and modeled (right) zonal means of the zonal wind at $60^{\circ} \mathrm{N}, 30 \mathrm{hPa}$ (upper panels), and of the temperature at $80^{\circ} \mathrm{N}, 30 \mathrm{hPa}$ (lower panels). NCEP analyses are based on observations from 1978-1998. Model data are averaged over 20 simulated years. Shaded areas indicate the interannual variability (minimum to maximum). Thin lines in the left panels represent analyses for the years 1998 and 1999.

- a very stable mid-winter in the model years 17/18 (purple lines).

A complete analysis of all northern model winters indicates that most of these features occur several times during the 20 -year simulation. Based upon the definition of a sudden major stratospheric warming, i.e. reversal of the zonal mean wind at $60^{\circ} \mathrm{N}, 10 \mathrm{hPa}$, from westerlies to easterlies, and reversal of the zonal mean temperature difference between polar latitudes and $60^{\circ} \mathrm{N}$, from negative to positive values, the model shows only one major warming event with a wind reversal down to $30 \mathrm{hPa}$. Due to the model's top level which is centered at $10 \mathrm{hPa}$, model data have been analyzed only for the $30 \mathrm{hPa}$ pressure level. However, five so-called strong minor warmings are found, connected with a reduction of the westerly winds to less than $10 \mathrm{~m} \mathrm{~s}^{-1}$. 15 minor warmings are simulated, associated with a reversal of the temperature difference and a clear decrease of the westerly wind speed.
Since a number of individual model years do not show any warming event, it is clear that minor warming happens two times in other years. The years containing warming events, however, do not accumulate in certain periods, which are more active than others. Although the modeled (climatological mean) arctic vortex still tends to be slightly more stable than seen in analyses of long-term observations, particularly in January, the dynamic variability of the present model version is substantially enhanced compared to former model versions.

\subsection{Stratospheric methane - a tracer indicating vertical mo- tion}

Vertical air movement inside the polar vortices is critical for polar ozone chemistry, particularly through its influence on the vertical distribution of inorganic chlorine species. In the 

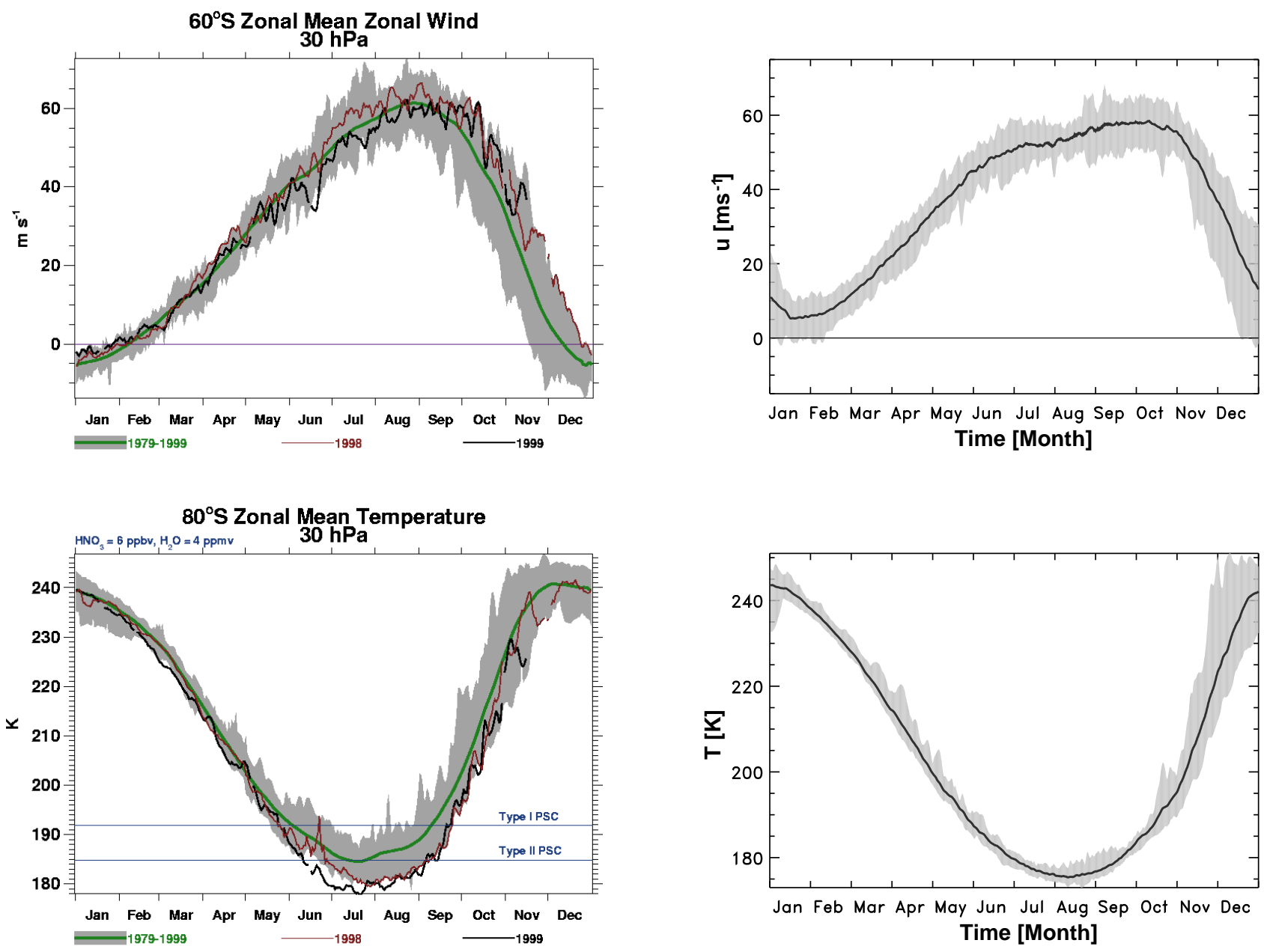

P. Newman (NASA), E. Nash (SM\&A), R. Nagatani (NCEP CPC)

Fig. 4. As Fig. 3, but for the southern hemisphere.
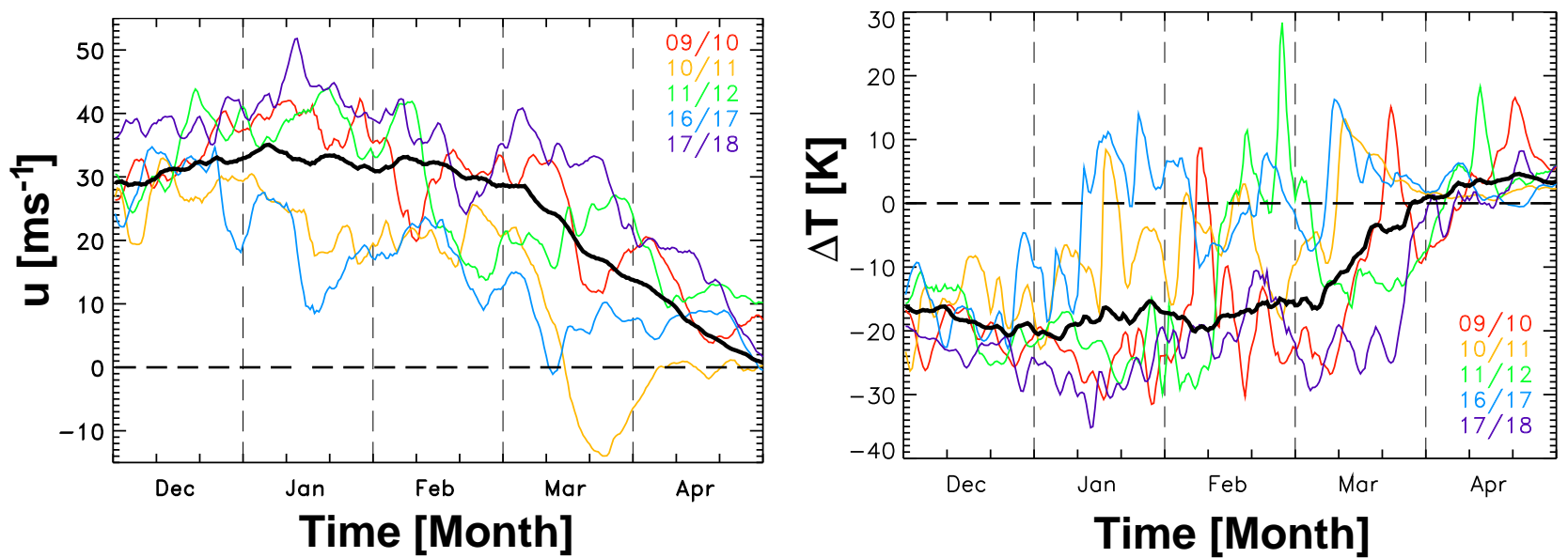

Fig. 5. 12-hourly averages of the modeled zonal means of the zonal wind at $60^{\circ} \mathrm{N}, 30 \mathrm{hPa}$ (left panel), and of the temperature difference between North Pole and $60^{\circ} \mathrm{N}, 30 \mathrm{hPa}$ (right panel) during winter and spring. Black lines represent the averages over 20 simulated years. Colored lines represent five selected model years with distinct dynamic conditions (see text). 


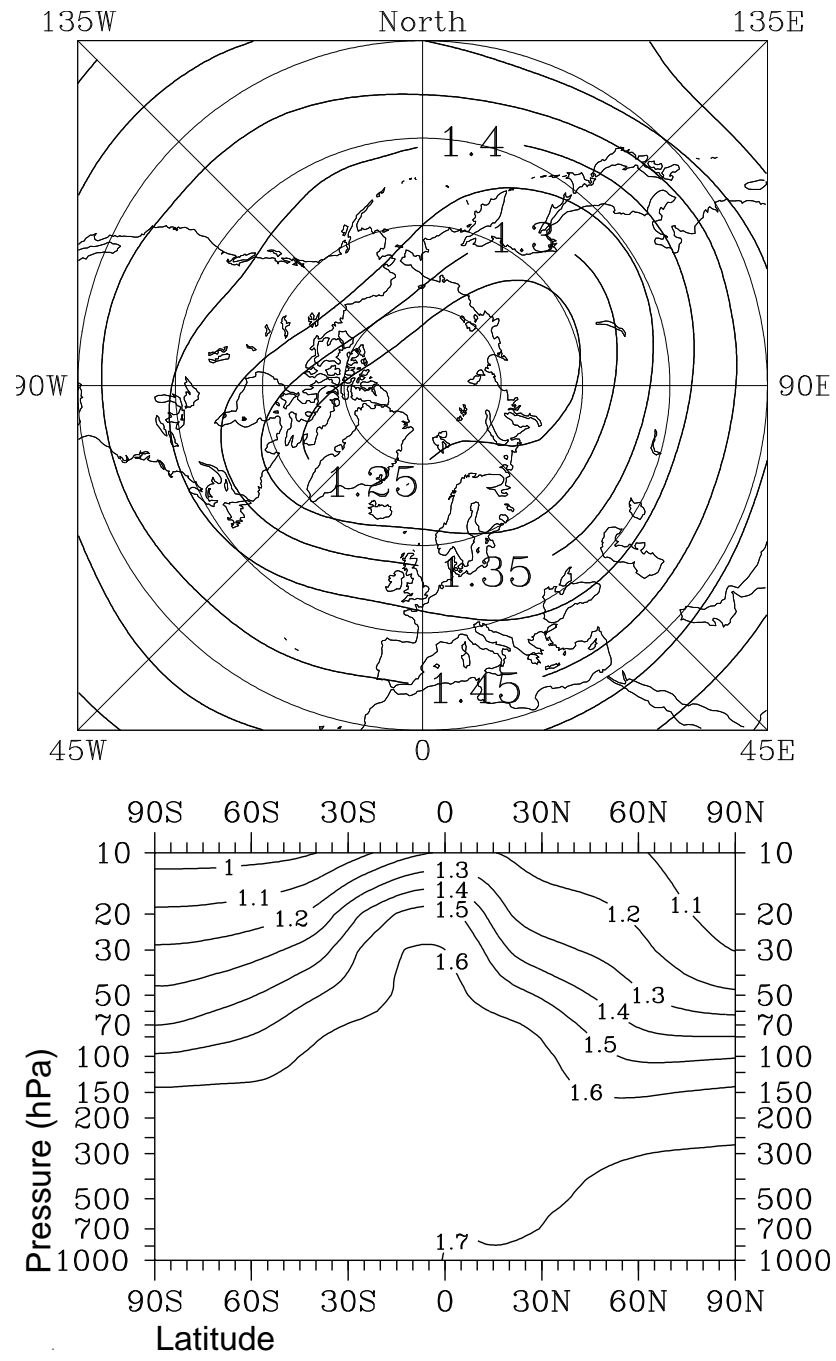

Fig. 6. Modeled methane mixing ratio in February, averaged over 20 simulated years; top: in the northern stratosphere at $50 \mathrm{hPa}$, contour lines are $1.1,1.15,1.2, \ldots, 1.6 \mathrm{ppmv}$; bottom: zonal mean height cross section (in ppmv).

last subsection, we have shown that the E39/C model is able to reproduce, to a large extent, the dynamic variability of the lower stratosphere in the northern hemisphere. This is remarkable, because a model with a top layer at $10 \mathrm{hPa}$ may be expected to have difficulties in consistently representing the effects of stratospheric overturning on the lower stratosphere. Indeed, previous models with the top layer at $10 \mathrm{hPa}$ often turned out to be unable to describe the dynamics of the polar vortices during winter sufficiently well. For instance, Grewe et al. (1998) reported shortcomings of the lower stratosphere dynamics at high latitudes in the ECHAM3/CHEM model concerning the vertical motion inside the polar vortex during winter. They calculated mean downward velocities between $0.006 \mathrm{~cm} \mathrm{~s}^{-1}$ and $0.06 \mathrm{~cm} \mathrm{~s}^{-1}$ at $50 \mathrm{hPa}$, whereas mean downward velocities between $0.05 \mathrm{~cm} \mathrm{~s}^{-1}$ and $0.08 \mathrm{~cm} \mathrm{~s}^{-1}$ were derived from observations (Tuck, 1989; Schoeberl et al., 1992; Rosenfield et al., 1994; Müller et al., 1996). Steil et al. (1998) even reported sporadic upward movements of air inside the polar vortices (compare their Fig. 10), which seem to be unrealistic. This shortcoming had important consequences for the distribution of chemical species and, therefore, for the rate of chemical reactions, including heterogeneous chemical ozone loss inside the polar vortices.

Since methane is chemically inert during polar night, it may be regarded as a suitable tracer of motion. Figure 6 displays the climatological means of modeled methane mixing ratio at $50 \mathrm{hPa}$ in February, as geographical distribution and as the zonal mean depending on altitude and latitude during northern hemisphere winter (DJF). In agreement with HALOE observations (see Steil et al., 1998), the area covered by the stratospheric vortex is characterized by reduced methane mixing ratios relative to air outside the vortex, which originate from the downward motion of air (diabatic descent) inside the vortex. In the model, the rate of descent inside the vortex is increasing with altitude, which is in agreement with observations, but it is also obvious that the descent becomes weaker at altitudes around $70 \mathrm{hPa}$ and below. This may be taken as an indication for an upper boundary effect. Additionally, the mean horizontal gradient of methane in the model appears to be smaller than observed. Müller et al. (1996) reported higher gradients from measurements taken during the winters $1991 / 1992$ to $1994 / 1995$. It is, however, important to note that the descent in northern winter is highly variable with stronger downward motions in cold and stable winters, such as those in the beginning 1990s. The modeled mean vertical downward velocity inside the polar vortex at $50 \mathrm{hPa}$ ranges between $0.079 \mathrm{~cm} \mathrm{~s}^{-1}$ and $0.104 \mathrm{~cm} \mathrm{~s}^{-1}$ and is in fair agreement with the above mentioned analyses. The results for the southern hemisphere (not shown) are qualitatively similar to the northern hemisphere. However, again the meridional methane gradient seems to be weaker than observed, indicating that the descent inside the antarctic vortex is not strong enough, at least at altitudes below $20 \mathrm{~km}$ (see also next subsection).

In summary, we conclude that the model is able to simulate fairly well the descent of air inside the arctic vortex during winter. The simulated descent in the lower part of the southern vortex seems to be underestimated.

\subsection{Ozone}

\subsubsection{Ozone columns}

In order to check the model's ability to simulate upper tropospheric and lower stratospheric chemistry, we first look at simulated total ozone. Its geographical, seasonal, and interannual variability is compared to observations. Figure 7 displays the temporal evolution of the modeled zonal mean total ozone throughout 20 model years. The most prominent features in the total ozone distribution, i.e. the spring maxima in both hemispheres, the tropical minimum, and the antarctic ozone hole in October, are clearly reproduced. The influence of the arctic vortex circulation regime on total ozone can be identified, with low total ozone in winters with a stable 

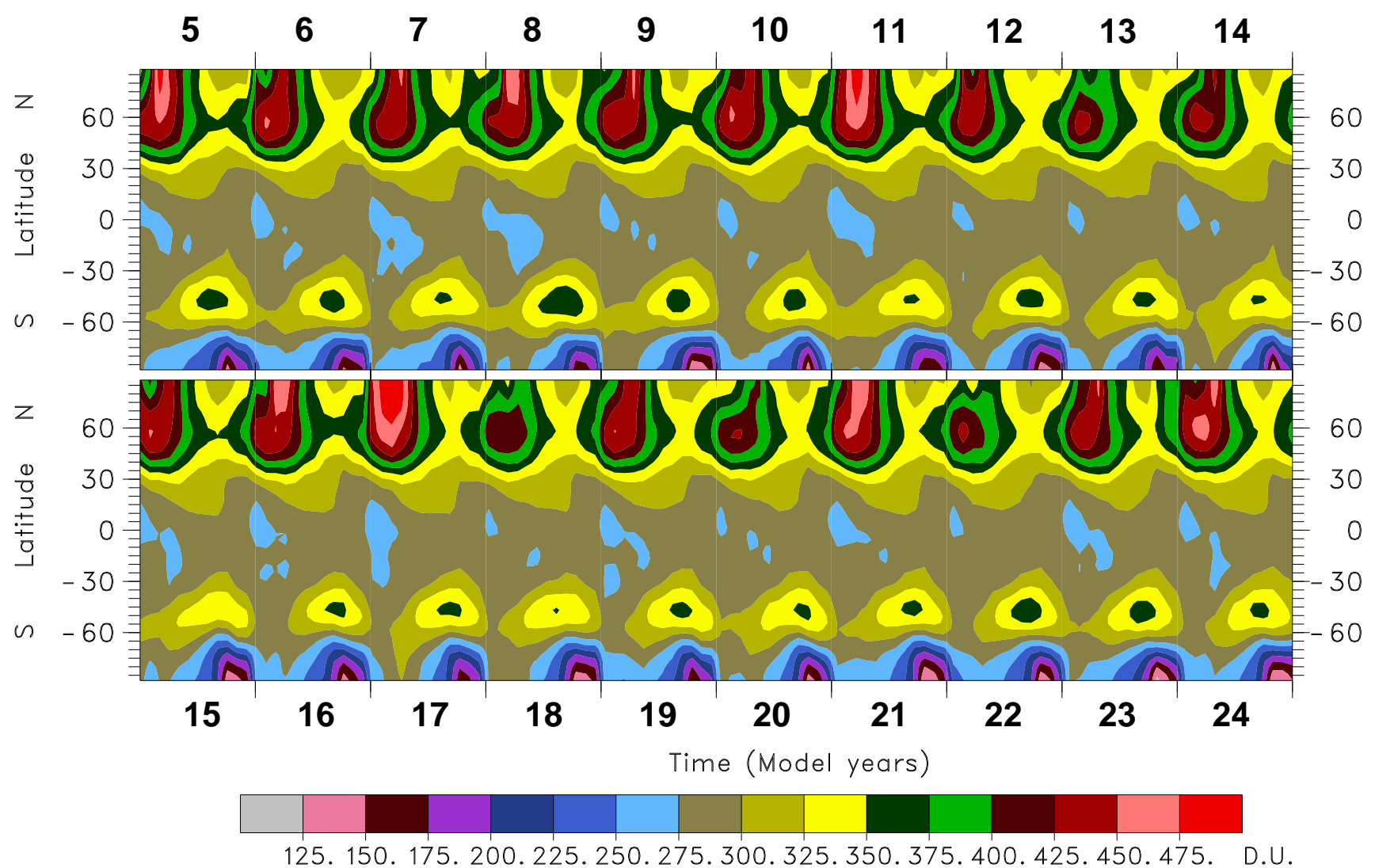

Fig. 7. Temporal evolution of modeled zonal mean total ozone (Dobson Units) over 20 simulated years.

vortex (e.g. model year 17/18) and high total ozone in dynamically active winters (e.g. 16/17). Apparently, the model has reached a quasi-steady state after the 4 year spin-up and does not show a significant drift, neither in total ozone nor in any other parameter.

Zonal mean total ozone averaged over the 20 simulated years is compared to an ozone climatology determined from ground-based measurements performed between 1985 and 1997 (Fig. 8). In tropical regions as well as in the northern hemisphere mid- and high latitudes, the seasonal variations of simulated total ozone are in general agreement with observations. Nevertheless, absolute total ozone values are overestimated by approximately 25 Dobson Units.

In the southern mid- and high latitudes, annual mean total ozone is simulated close to observations, but the seasonal variability of total ozone shows some characteristic deficiencies. As far as high southern latitudes are concerned, they could, at least partly, be attributed to the dynamic deficiencies, i.e. the temperature bias, and the weak descent of air inside the vortex in the lowermost stratosphere, which has been discussed in Sects. 3.1 and 3.2. The mid-latitude Austral spring maximum occurs in August/September, approximately one month earlier than observed. The temporal occurrence of the antarctic ozone hole is in agreement with observations, i.e. minimum total ozone values occur in late September/early October. Total ozone drops below
125 DU inside the antarctic vortex in agreement with satellite observations performed during the 1990s (Total Ozone Mapping Spectrometer, TOMS, and Global Ozone Mapping Experiment, GOME), and ground-based observations. However, total ozone is lower than climatological mean values of ground-based observations from the years 1985-1997 (Fig. 8 ), although the contribution of bromine to ozone destruction is absent in the model. This may be compensated by the effects of the cold bias, which yield a strong activation of chlorine (see Sect. 3.5).

\subsubsection{Ozone profiles at selected stations}

Measurements performed from ozone sondes, which were regularly launched at several sites over multiple years during the second half of the 1980s, are used to validate the model results. Data from six sites located between $74^{\circ} \mathrm{N}$ and $90^{\circ} \mathrm{S}$ are displayed by squares in Fig. 9 (Komhyr et al., 1989; Oltmans et al., 1989). Model data (solid lines) represent seasonal averages from 20 simulated model years. Horizontal bars indicate the interannual variability (two standard deviations of seasonal values obtained for individual model years). Horizontally, model data have been interpolated linearly to the location of the observational sites.

At the tropical stations in Hilo $\left(19^{\circ} \mathrm{N}\right)$ and Samoa $\left(14^{\circ} \mathrm{S}\right)$, the agreement is close, both in the troposphere and strato- 

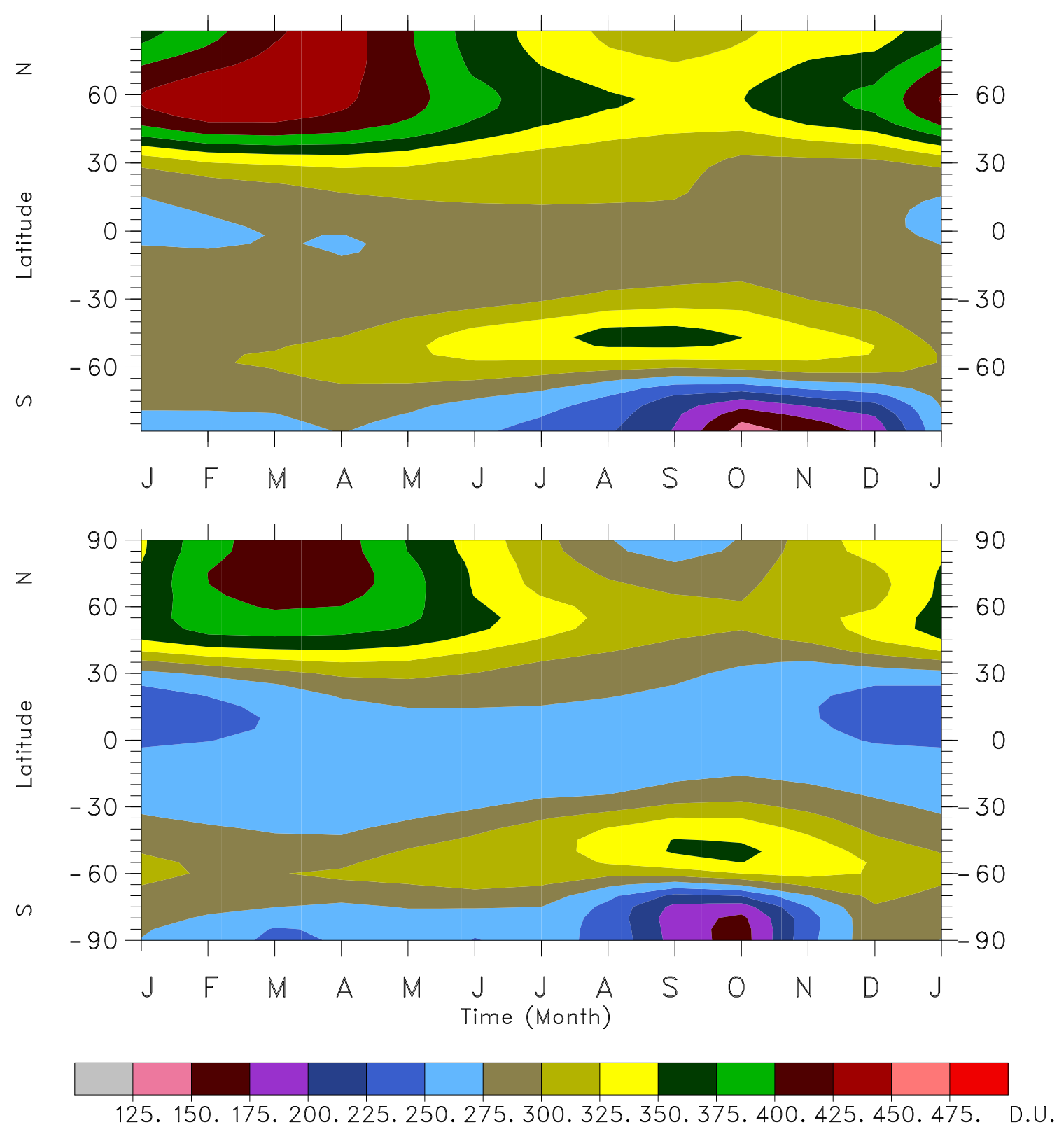

Fig. 8. Modeled (upper panel) and observed (lower panel) climatological zonal mean total ozone (Dobson Units). Model results are averaged over 20 simulated years. Observed data represent averages over the years 1985-1997 (Bojkov et al., 1999; Fioletov, pers. comm. 1999).

sphere. Only at levels around $30 \mathrm{hPa}$, model concentrations are slightly higher than the observations. At higher latitudes, low ozone concentrations representative for tropospheric air extend up to somewhat too high altitudes, indicating an overestimated tropopause height. This shortcoming is strongest near the South Pole. Although less pronounced, it is also present in the northern hemisphere, for example, over the stations in Resolute, Canada $\left(74^{\circ} \mathrm{N}\right)$, and Pt. Barrow, Alaska $\left(71^{\circ} \mathrm{N}\right.$, not shown). In contrast, maximum ozone concentrations in the stratosphere are generally in good agreement with observations at all extra-tropical stations in all seasons. The only exception occurs in Antarctica, particularly during winter and spring, where modeled ozone profiles in the low- ermost stratosphere differ substantially from observations. This may be attributed to the cold bias problem and to the too weak descent of air-masses inside the polar vortex in the lowermost stratosphere.

To investigate the shortcomings in the south polar region in more detail, an analysis of a deep ozone hole situation is displayed in Fig. 10, which is representative for all model years. As observed, ozone is almost completely destroyed in a narrow layer. The critical deficiency of the disturbed ozone profile in the model is that this layer is not simulated at altitudes below $50 \mathrm{hPa}$ (e.g. WMO, 1999). It would be interesting to see if this deficiency is significantly reduced employing MA-GCMs with chemistry. Pawson et al. (2000) 


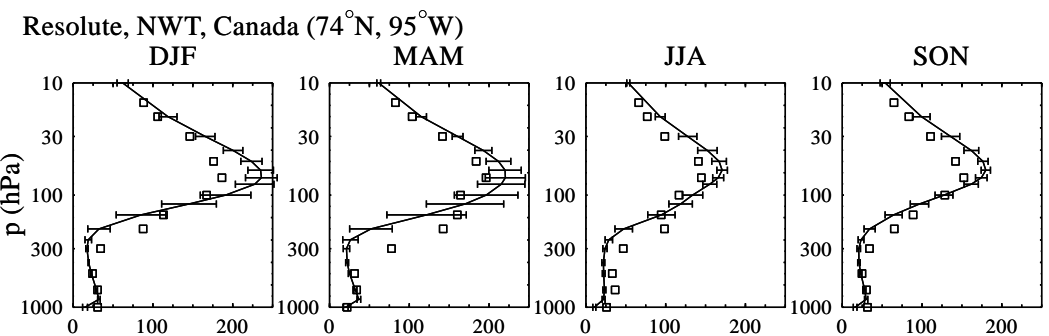

Boulder, Colorado $\left(40^{\circ} \mathrm{N}, 105^{\circ} \mathrm{W}\right)$

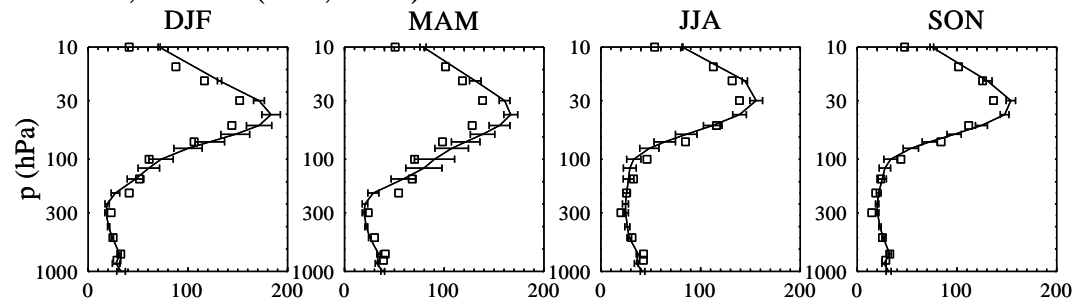

Hilo, Hawaii $\left(19^{\circ} \mathrm{N}, 155^{\circ} \mathrm{W}\right)$

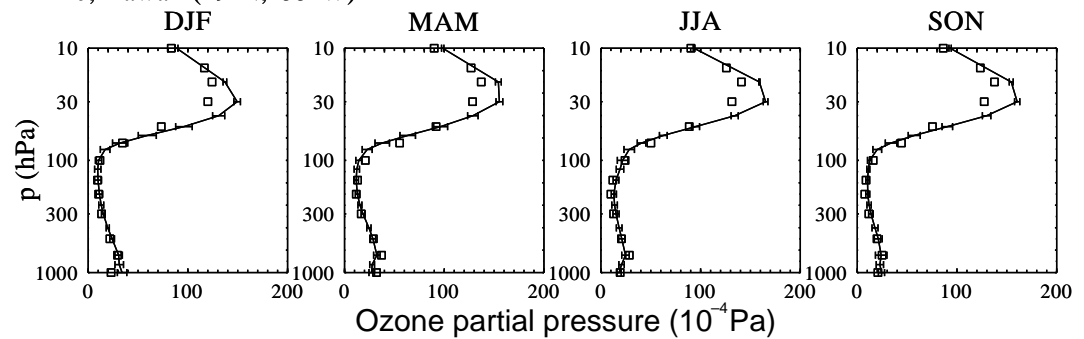

American Samoa $\left(14^{\circ} \mathrm{S}, 170^{\circ} \mathrm{W}\right)$

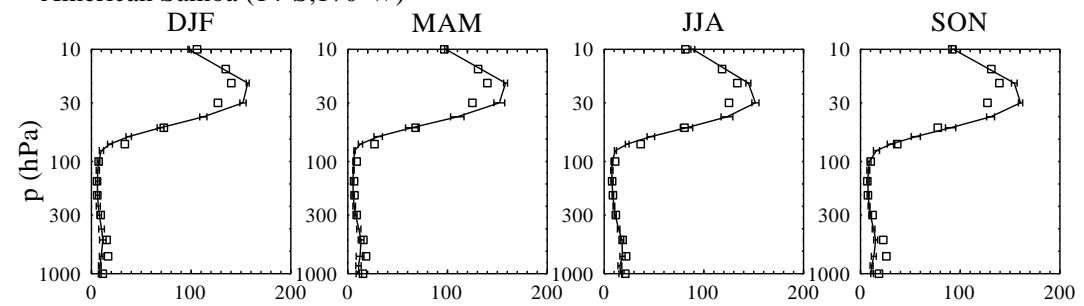

Lauder, New Zealand $\left(45^{\circ} \mathrm{S}, 170^{\circ} \mathrm{E}\right)$

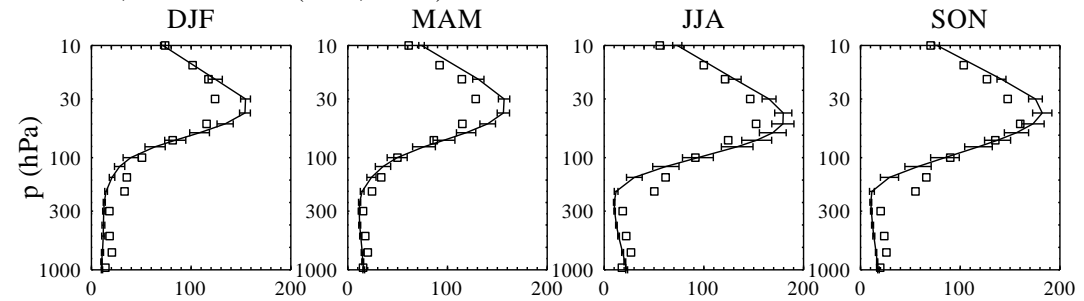

South Pole $\left(90^{\circ} \mathrm{S}\right)$

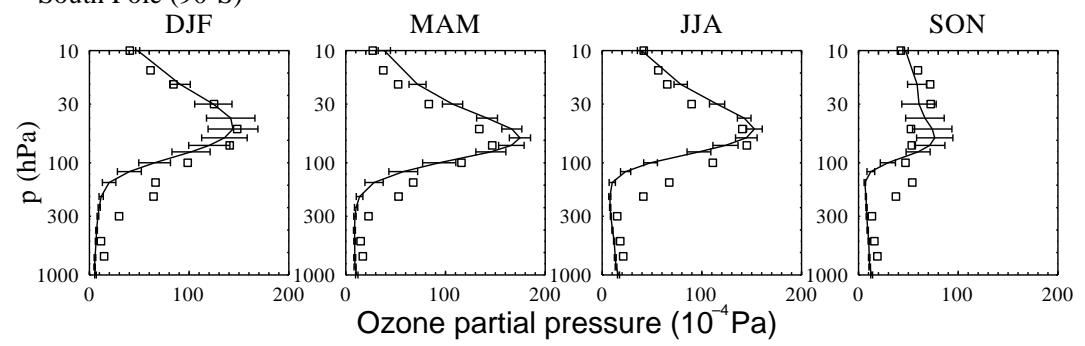

Fig. 9. Modeled (lines) versus observed (squares, Komhyr et al., 1989; Oltmans et al., 1989) climatological ozone profiles at selected stations for the four seasons. Horizontal bars indicate modeled interannual variability (two standard deviations). Observations have been taken from 1983 to 1989. 


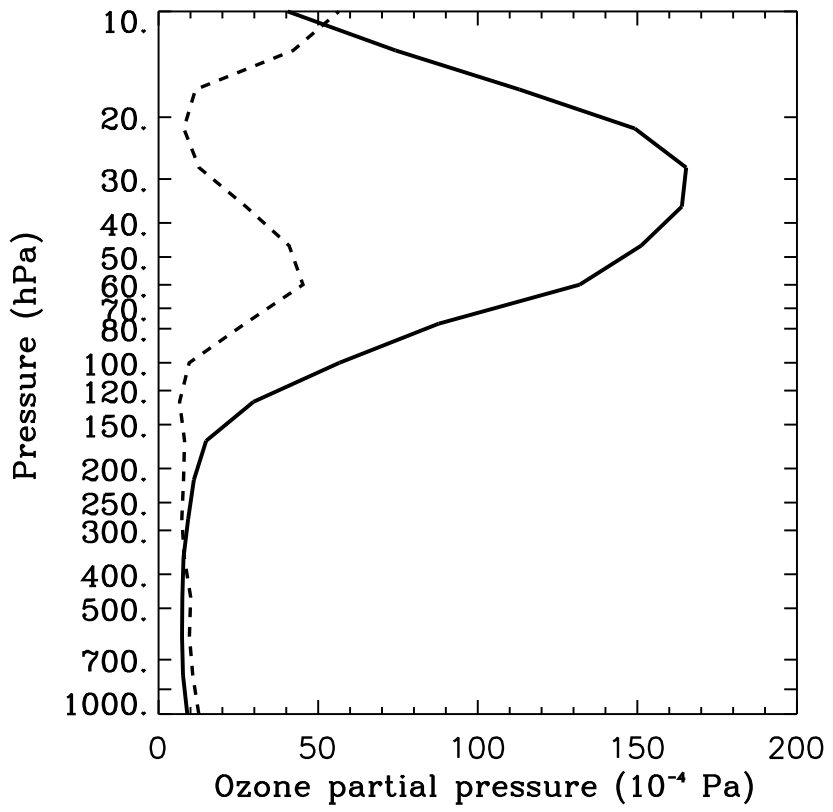

Fig. 10. Modeled ozone profiles near the South Pole for a single day in August (solid line) and in October (dotted line).

showed that the cold bias is also obvious in most MA-GCMs; The reasons for that are still unclear. On the other hand, in MA-GCMs, the downward transport of airmass inside the polar vortices should be improved, which should yield a better reproduction of disturbed ozone profiles in Austral spring.

\subsubsection{Zonal mean ozone mixing ratios}

In this section, we compare simulated zonal mean vertical ozone distributions and their seasonal evolution to the ozone climatology of Fortuin and Kelder (1998, hereafter referred to as FK98). The FK98 ozone climatology is based on a combination of ozone sonde measurements from 30 stations around the globe and satellite observations performed by the Solar Backscattered Ultraviolet System (SBUV, SBUV/2) and by TOMS. The climatological data represent the time period 1980-1991. Modeled zonal mean ozone mixing ratios averaged over 20 simulated years are displayed in Fig. 11 for January, April, July, and October. In order to allow an easy comparison between simulated and observed ozone mixing ratios, we calculated differences (model minus observed) after interpolating the observed data to the model grid (Fig. 12). The general structures of the vertical distributions of ozone mixing ratios and their seasonal variability are quite similar in model and observations. In the lower stratosphere (around $20 \mathrm{~km}$ ) in both hemispheres, simulated seasonal maxima occur in winter/spring, in agreement with FK98. Near the tropopause, the difference field suggested some deficiencies in the modeled ozone distribution. Generally, modeled ozone mixing ratios appear to be underestimated near the tropopause and in the lowermost stratosphere. In contrast, modeled ozone concentrations in the uppermost model levels are generally between 0.5 and 1 ppmv higher than those given by FK98. The dipole structure in the difference field, which can be also noticed in some of the station comparisons (Fig. 9), may be regarded as an indication of remaining model problems with respect to stratospheretroposphere exchange (Rasch and Lawrence, 1998; Timmreck et al., 1999). Unfortunately, we cannot estimate the quality of the employed data set of FK98, with respect to error bars at different geographical regions and altitudes. However, it is evident that in some regions the FK98 climatology differs substantially from the ozone sonde observations mentioned in Sect. 3.3.2, particularly in the southern hemisphere, where ozone sonde observations are sparse. Part of the differences may also be attributed to an inconsistency in the time period, for which model simulations and observations are compiled.

As will be discussed in Sect. 3.5, maximum $\mathrm{ClO}_{\mathrm{x}}$ concentrations in the model occur in the antarctic stratosphere in winter and early spring at unrealistically high altitudes, which is consistent with the ozone hole profile presented in Fig. 10. This may also contribute to the underestimation of ozone concentrations around $30 \mathrm{hPa}$ and the overestimation in the lowest parts of the stratosphere (around $70 \mathrm{hPa}$ ), apparent in Fig. 12.

Overall, the seasonal variability of simulated ozone concentrations is in good agreement with observations. Particularly, the model yields stratospheric and tropospheric spring/summer ozone maxima at mid-latitudes, and flat seasonal variations in the tropics.

\subsection{Stratospheric water vapour concentrations}

Figure 13 displays the modeled zonal mean water vapour mixing ratio averaged over the 20 simulated years for the four seasons. Most obvious is the huge vertical gradient in the troposphere following the temperature gradient. Low water vapour mixing ratios occur near the tropical tropopause where temperatures are low. Since the general (Hadley) circulation is directed upward in the tropics, $\mathrm{H}_{2} \mathrm{O}$ mainly enters the stratosphere in tropical regions. In the absence of in situ sources and sinks, water vapour mixing ratios would, therefore, be almost constant throughout the stratosphere and mainly controlled by tropical tropopause temperatures. However, methane oxidation constitutes an in situ source of water vapour. This source gives a substantial contribution to the stratospheric water vapour budget, resulting in increasing stratospheric $\mathrm{H}_{2} \mathrm{O}$ mixing ratios towards higher latitudes and altitudes, except for regions with strong dehydration. Modeled water vapour mixing ratios are compared to observations from the Halogen Occultation Experiment (HALOE) instrument on the Upper Atmospheric Research Satellite (UARS, Harries et al., 1996; Russell et al., 1993). HALOE sunset observations (http://haloedata.larc.nasa.gov/home.html) have been evaluated with data retrieval version 19 for the years 1993-1996. They are used to calculate the bi-monthly mean values displayed in Fig. 14. In spring and fall of both hemispheres, 

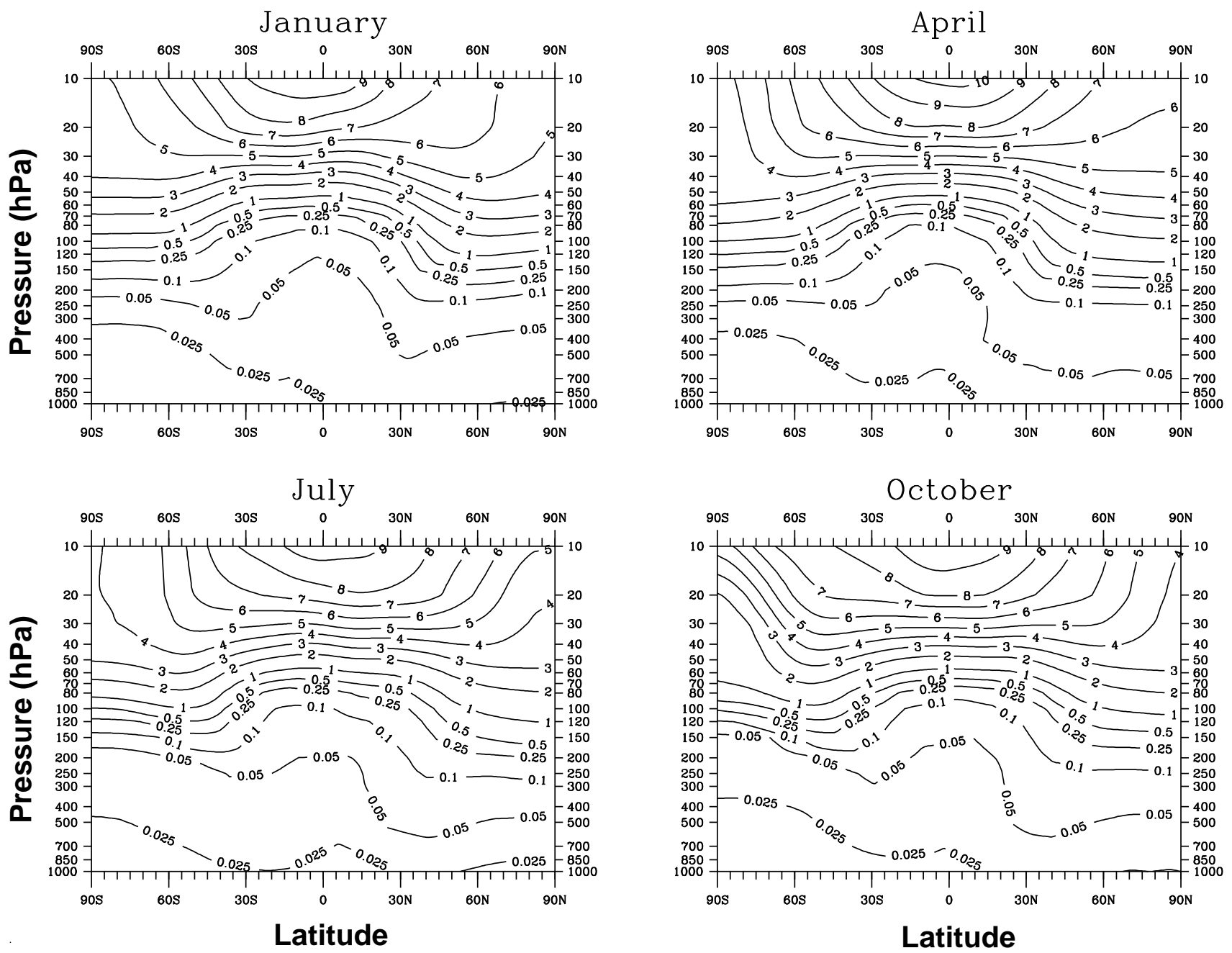

Fig. 11. Climatological monthly averages of the zonal mean ozone mixing ratios (ppmv) in January, April, July, and October, as simulated by E39/C.

the data coverage from HALOE is sufficient. For austral winter (JJA), the gap in the HALOE data over Antarctica is filled by MLS data (http://hyperion.gsfc.nasa.gov/Analysis/ UARS/urap/home.html; Pumphrey (1999)). In the arctic winter, MLS does not suggest any dehydration. Hence, extrapolation from mid-latitude HALOE data to high latitudes is feasible.

The comparison between model and satellite observations reveals that the meridional gradient in stratospheric water vapour mixing ratios can be qualitatively reproduced, which is an important improvement compared to conventional AGCMs. This can directly be attributed to the inclusion of the chemical source of $\mathrm{H}_{2} \mathrm{O}$. Water vapour mixing ratios near the tropical tropopause are slightly overestimated, particularly during northern summer and fall. $\mathrm{H}_{2} \mathrm{O}$ mixing ratios in the stratosphere are systematically higher than in the HALOE observations. This may indicate insufficient ascent due to the low upper boundary. However, another possibility may be that the sub-tropical transport barrier is not adequately represented. Currently, it is not possible to give a comprehensive explanation for this behaviour on the basis of the performed simulation. It might also depend on an apparent temperature bias near the model's tropopause and on numerical vertical diffusion in the model.

Dehydration in antarctic winter, though also apparent in the observational data, is overestimated in the model. This behaviour can directly be attributed to the cold bias in antarctic vortex temperatures, as discussed in Sect. 3.1.

\subsection{Chlorine activation and deactivation}

Chlorine activation, i.e. the transformation of long-lived chlorine reservoir species to highly reactive compounds, is crucial for heterogeneous chemical ozone destruction. Due to the limited number of multi-annual global observations, we compare results of the E39/C model with those obtained by the chemical transport model SLIMCAT (Chipperfield, 1999), which uses observed meteorological input data from distinct years. SLIMCAT is able to simulate a 

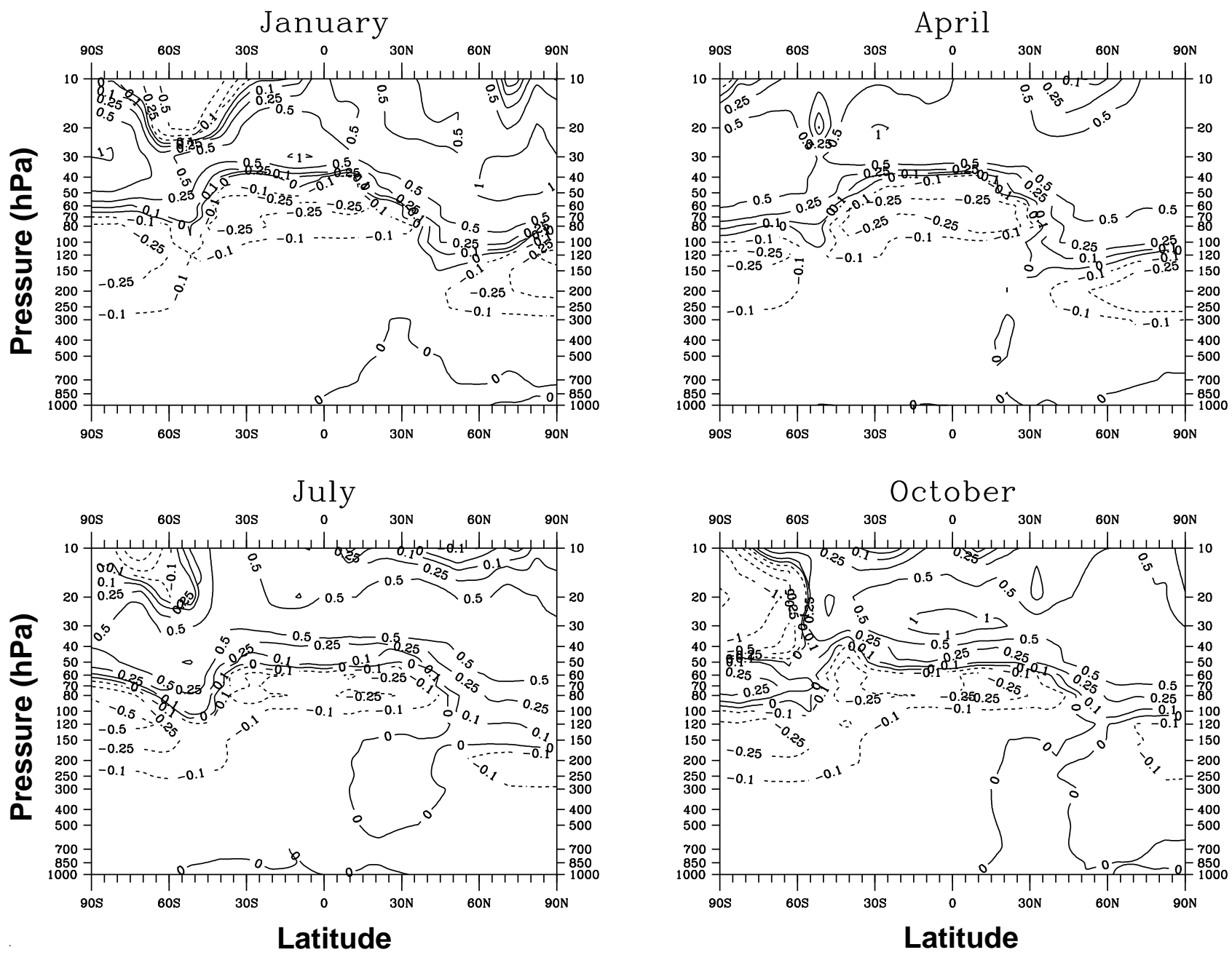

Fig. 12. Difference of modeled and observed (Fortuin and Kelder, 1998) monthly averages of the zonal mean ozone mixing ratios (ppmv) in January, April, July, and October. Positive differences indicate higher ozone concentrations in the model.

reasonable interannual variability in chlorine activation, particularly in the northern hemisphere winter (Chipperfield et al., 1996; Hansen and Chipperfield, 1999), as well as the strong chlorine activation in the southern hemisphere winter. Inter-hemispheric differences in the recovery of the reservoir gases $\mathrm{HCl}$ and $\mathrm{ClONO}_{2}$ noticed in the UARS observations (Douglass et al., 1995), are also reproduced by SLIMCAT.

Over Antarctica, $\mathrm{ClO}_{\mathrm{x}}$ mixing ratios simulated by E39/C (Fig. 15) peak at $2.7 \mathrm{ppbv}$ in mid-winter at the $30 \mathrm{hPa}$ level. Given the mean chlorine loading in the model stratosphere of approximately $3.3 \mathrm{ppbv}$, this result indicates a very high level of chlorine activation. It is in good agreement with the results of Chipperfield (1999) who fixed the total chlorine loading in his model to $3.6 \mathrm{ppbv}$, and calculated a chlorine activation with a peak $\mathrm{ClO}_{\mathrm{x}}$ mixing ratio of $2.7 \mathrm{ppbv}$ on the $480 \mathrm{~K}$ isentrope surface (corresponding to approximately $50 \mathrm{hPa}$ ). The high level of chlorine activation (up to $80 \%$ of total chlorine) simulated with E39/C may partly be attributed to the cold bias in the model's antarctic lower stratosphere, which is most pronounced at $30 \mathrm{hPa}$, as discussed in Sect. 3.1. The decay of $\mathrm{ClO}_{\mathrm{x}}$ in polar spring is reasonably captured by E39/C. In the core of the southern hemisphere polar vortex, $\mathrm{ClO}_{\mathrm{x}}$ is mainly converted into the reservoir gas $\mathrm{HCl}$ with mixing ratios reaching approximately $2 \mathrm{ppbv}$ at $70^{\circ} \mathrm{S}, 30 \mathrm{hPa}$ in October (not shown). The $\mathrm{ClONO}_{2}$ collar at sub-polar latitudes during spring constitutes another prominent feature known from the observed antarctic stratosphere (Douglass et al., 1995). It evolves from the breakdown of $\mathrm{ClO}_{\mathrm{x}}$, when the chlorine reservoir species $\mathrm{ClONO}_{2}$ recovers due to increasing photochemical activity during polar spring. It is also reproduced by $\mathrm{E} 39 / \mathrm{C}$ (not shown), with $\mathrm{ClONO}_{2}$ mixing ratios within the collar peaking at $1.6 \mathrm{ppbv}$, in good agreement with SLIMCAT, which calculated peak values of 1.5 to $1.8 \mathrm{ppbv}$. However, maximum $\mathrm{ClONO}_{2}$ mixing ratios in $\mathrm{E} 39 / \mathrm{C}$ occur at too high altitudes ( 20 to $30 \mathrm{hPa}$ in October). This may, again, be a consequence of the model's temperature bias in winter.

In the northern hemisphere, modeled chlorine activation is 

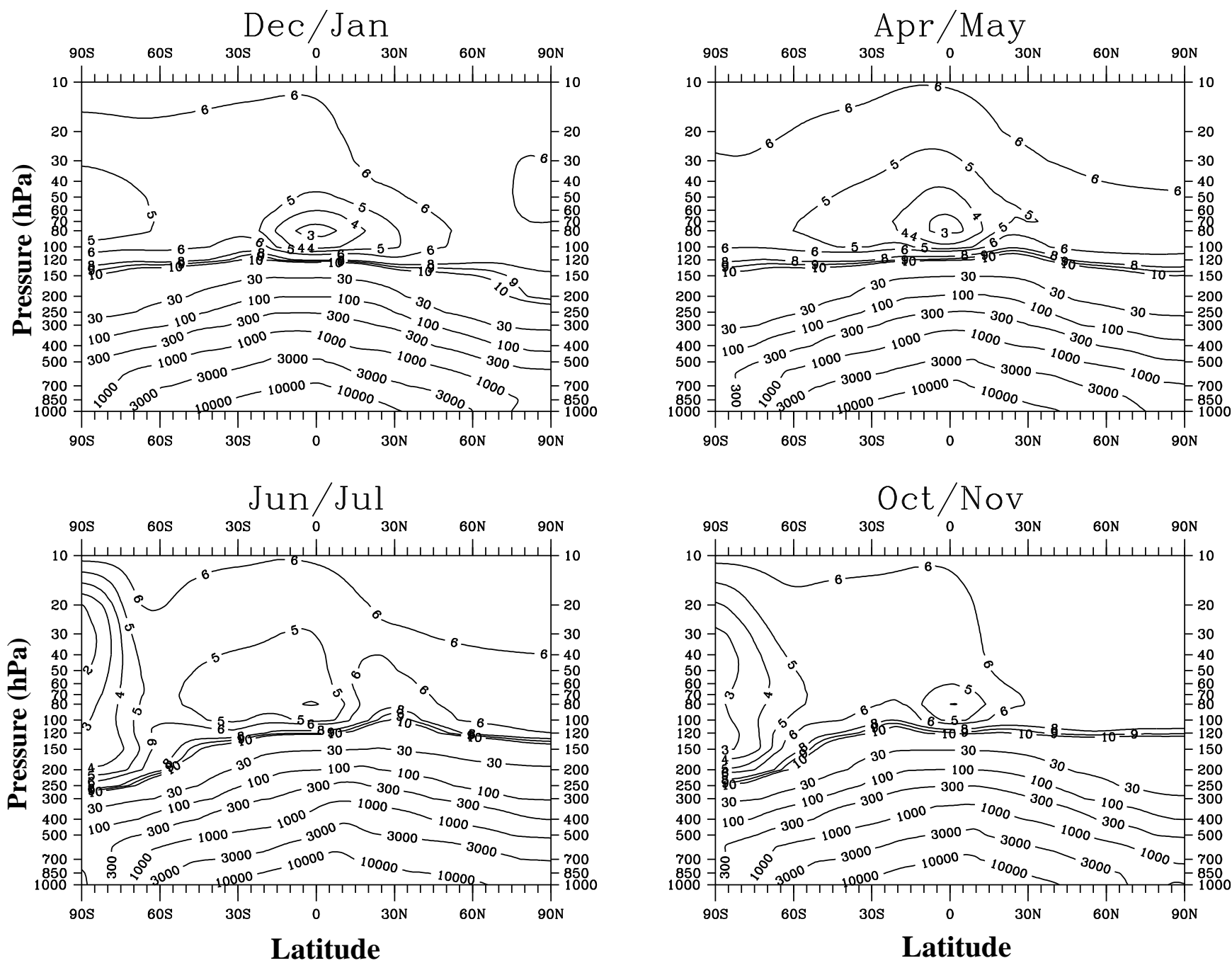

Fig. 13. Monthly averages of the zonal mean water vapour mixing ratios (ppmv) averaged over 20 years for December/January, April/May, June/July, and October/November, as simulated by E39/C.

clearly lower than in the southern hemisphere. $\mathrm{ClO}_{\mathrm{x}}$ mixing ratios peak at $2.2 \mathrm{ppbv}$ in January at $30-40 \mathrm{hPa}$ (Fig. 15). The high interannual standard deviation of $0.6 \mathrm{ppbv}$ stresses the strong influence of the dynamic variability on chlorine activation. This result is in agreement with the SLIMCAT simulations and analyses of observations (Müller et al., 1996, 1997a,b; Rex et al., 1998, 1999; von der Gathen et al., 1995), which also indicate a strong interannual variability in $\mathrm{ClO}_{\mathrm{x}}$ mixing ratios and related ozone changes during the northern winters 1991/92 to 1996/97. In the northern hemisphere, activated chlorine is first converted to $\mathrm{ClONO}_{2}$ during February and March, and recovers back to $\mathrm{HCl}$ only later, in good agreement with observations.

\section{Discussion}

As presented in the previous section, E39/C quite reasonably reproduces observations. What are the reasons for this be- haviour? Why are dynamic features in the northern stratosphere in much closer agreement to observations than in any earlier ECHAM model version? Most likely, the answer consists of a combination of at least two factors. First, the inclusion of the orographic gravity wave drag parameterization in ECHAM4, which was absent in ECHAM3, with T21 horizontal resolution, plays a critical role. Second, the enhanced vertical resolution contributes to the improvements.

Since too stable stratospheric polar vortices in winter and spring, i.e. too strong westerlies and too low temperatures, particularly in the northern hemisphere, constitute a general problem in many AGCMs, it may be worthwhile to discuss this problem in more detail. Several authors have claimed that including a suitable gravity wave drag parameterization in GCMs is important to improve the model dynamics. For instance, Rind et al. (1988) showed that, in the MA-GCM operated at Goddard Institute for Space Studies (GISS) in New York, sudden stratospheric warmings appear in northern 

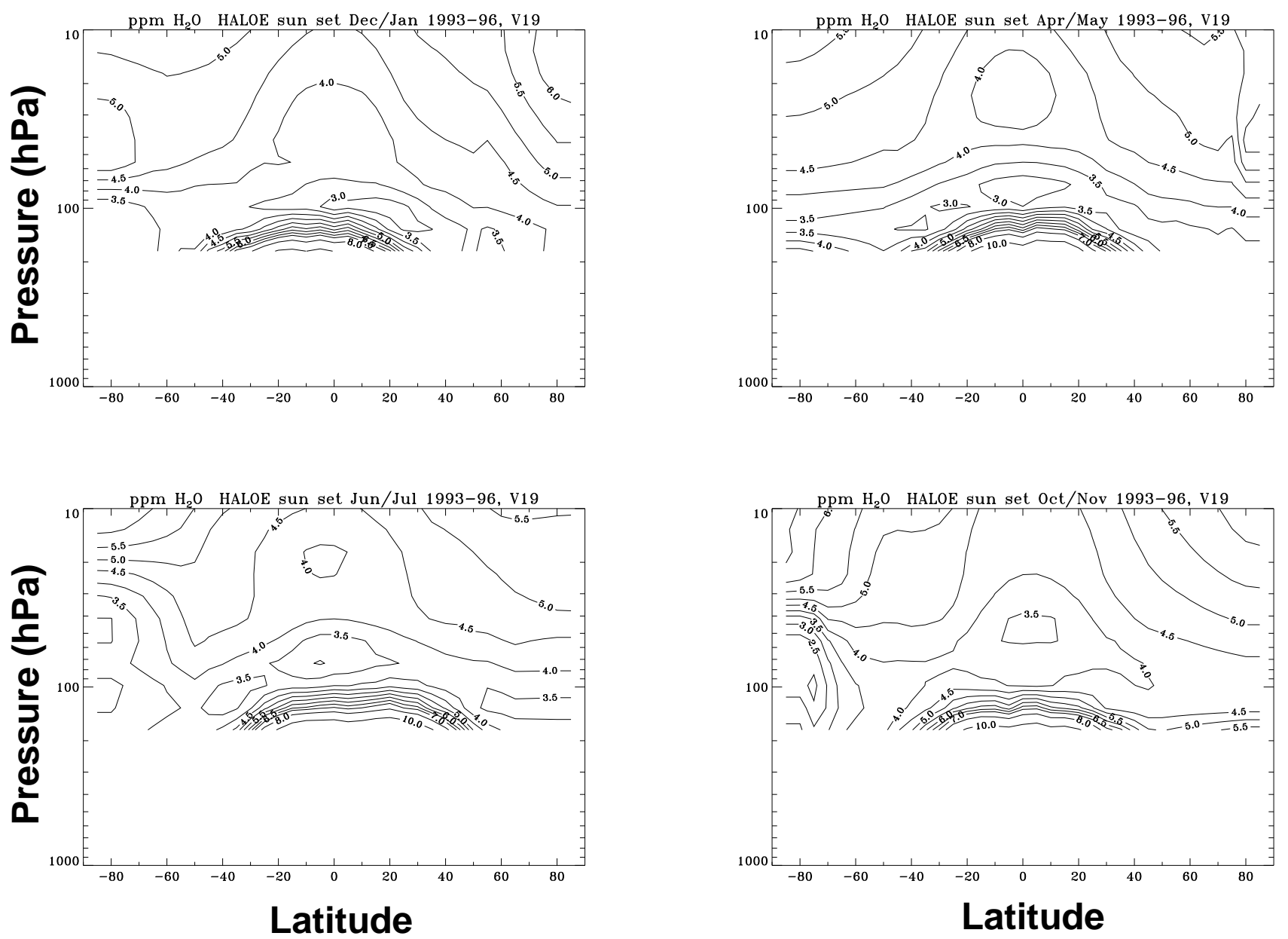

Fig. 14. Climatological monthly averages of the zonal mean observed water vapour mixing ratios (ppmv) for December/January, April/May, June/July, and October/November. HALOE satellite observations for the years 1993-1996 have been evaluated using data retrieval version 19. Data gaps in antarctic polar night have been filled by MLS observations (see text). The vertical axis is chosen as in Fig. 13 to allow an easy comparison. Below $174 \mathrm{hPa}$, no reliable satellite observations are available.

winters only if a gravity wave drag scheme is included.

Roeckner et al. (1992) investigated the influence of horizontal resolution (T21 versus T42) and of an orographic gravity wave drag parameterization (Miller et al., 1989) on the ability of the ECHAM3 model to reproduce climatological distributions of meteorological parameters. Lower stratosphere dynamics were significantly more realistic in the T42 model version, when a "well-tuned" gravity wave drag scheme was included. The increase in horizontal resolution alone did not lead to a thorough improvement of lower stratosphere dynamics. For example, the temperature distribution in the lower stratosphere at certain pressure levels was only reproduced in agreement with climatological analyses provided by ECMWF when the gravity wave drag was applied. The authors concluded that even low resolution GCMs seem to need an appropriate stratospheric drag in order to realistically maintain the momentum budget. Sausen et al. (1993) showed that the incorporation of a gravity wave drag parameterization in coarse resolution GCMs can cause a distinctly negative impact on the simulation if it is not tuned to the respective model system. For this reason, it was not applied in ECHAM model versions with a horizontal resolution lower than T30, like ECHAM3/CHEM. Investigations carried out during the development of ECHAM4 revealed that it was not necessary to modify the gravity wave scheme employed in ECHAM3 (T42) for ECHAM4, neither for the standard 19 level (L19) version (Roeckner et al., 1996) nor for the T30/L39(DLR) version employed in this work (Land et al., 1999).

It has been demonstrated that including the effects of non-orographic gravity waves, which are not considered in E39/C, can directly influence model dynamics (e.g. Manzini and McFarlane, 1998). However, non-orographic gravity waves cannot be adequately considered in E39/C, since these waves tend to break at altitudes above the top model layer. On the other hand, the effects of breaking gravity waves in the upper stratosphere and mesosphere can indirectly modify the dynamics of the lower stratosphere ('downward con- 

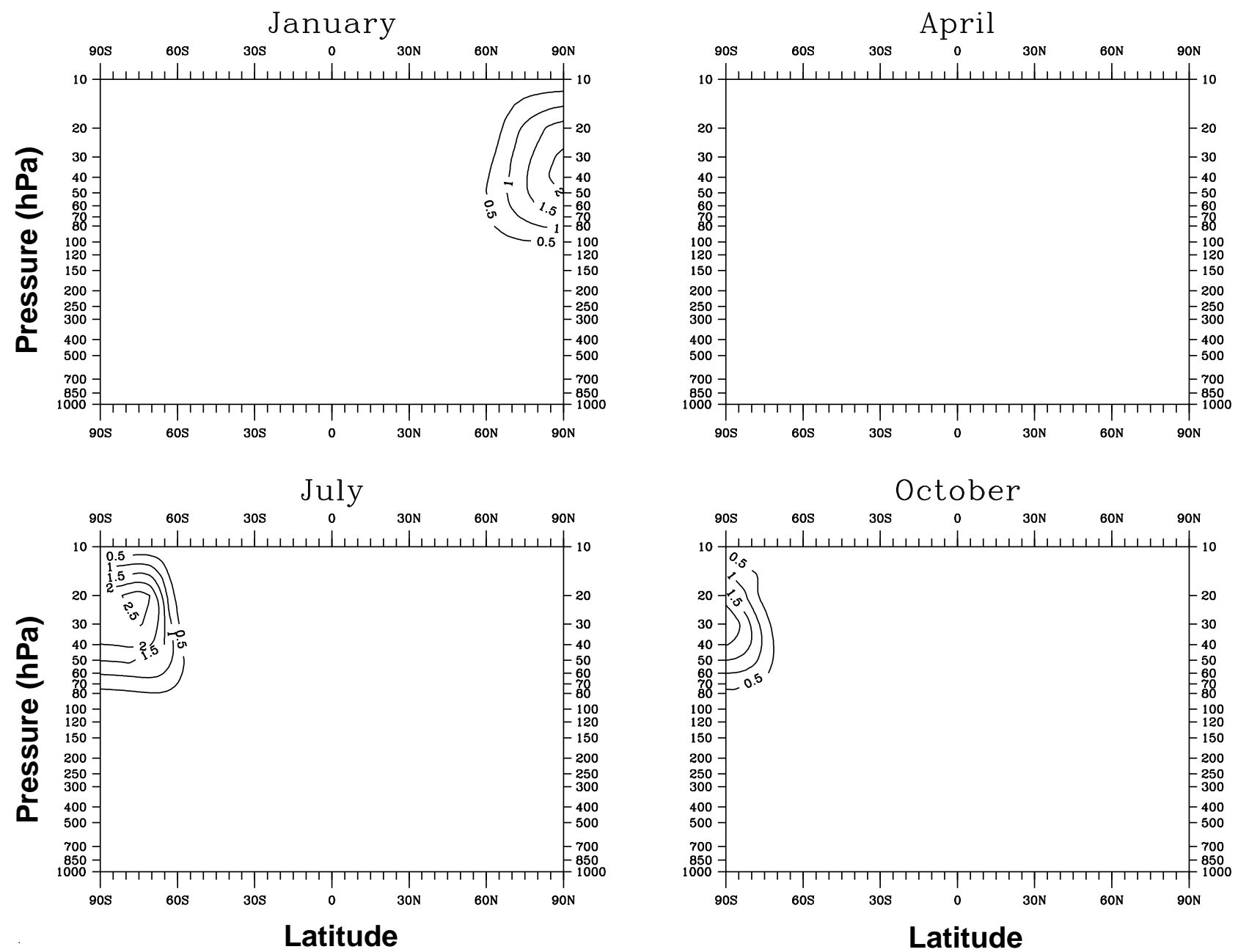

Fig. 15. Climatological monthly and zonal mean modeled $\mathrm{ClO}_{\mathrm{x}}$ mixing ratios (ppbv) for January, April, July, and October.

trol principle'). In this sense, neglecting these processes is certainly a shortcoming of E39/C. The quantitative consequences are hard to predict until a detailed intercomparison of the dynamic behaviour of MA-ECHAM4 and E39 has been performed.

Including orographic gravity wave drag is not the only reason for the improvements in stratospheric dynamics in E39/C relative to ECHAM3/CHEM. This can be seen from results of a sensitivity experiment performed with ECHAM4/ CHEM. The corresponding simulation is identical to the simulation described in Sect. 3 apart from a reduction of the vertical resolution back to the 19 levels of the standard ECHAM4 version. Analogously to Figs. 3 and 4, Fig. 16 shows the zonal mean winds at $60^{\circ} \mathrm{N}$ and $60^{\circ} \mathrm{S}$ (upper panels) and the zonal mean temperature at $80^{\circ} \mathrm{N}$ and $80^{\circ} \mathrm{S}$ (lower panels) from this sensitivity simulation for the $30 \mathrm{hPa}$ level. It clearly reveals that stratospheric dynamics, particularly in the Arctic, are characterized by a much more stable vortex in the L19 model version, even though the lower stratosphere equatorial zonal winds are permanent easterlies, since the model does not generate the QBO internally (see correspond- ing remarks in Sect. 3.1). Stratospheric winter temperatures inside the vortex are lower with a climatological mean as cold as $191 \mathrm{~K}$ in late December and early January, compared to $197 \mathrm{~K}$ in the L39 version (Fig. 3) and $200 \mathrm{~K}$ in the NCEP analyses. Consistently, zonal winds are stronger in the L19 simulation, peaking above $40 \mathrm{~m} \mathrm{~s}^{-1}$ in early January, compared to $35 \mathrm{~m} \mathrm{~s}^{-1}$ in the $\mathrm{L} 39$ version and $30 \mathrm{~m} \mathrm{~s}^{-1}$ in the NCEP analyses. The variabilities of temperature and wind are evidently suppressed in the L19 version relative to the L39 version. This indicates that enhanced vertical resolution helps to obtain a more realistic behaviour of lower stratosphere dynamics.

Bromine (Br) chemistry, which may lead to an additional ozone reduction, especially in the northern polar stratosphere (Müller, 1994; Danilin et al., 1996), is not included in our model. Model sensitivity studies (Chipperfield and Pyle, 1998) indicate that during recent time, stratospheric chlorine was by far the most important factor in determining the amount of polar ozone depletion. They concluded that stratospheric bromine would be of major importance for ozone depletion only if chlorine abundances decreased 

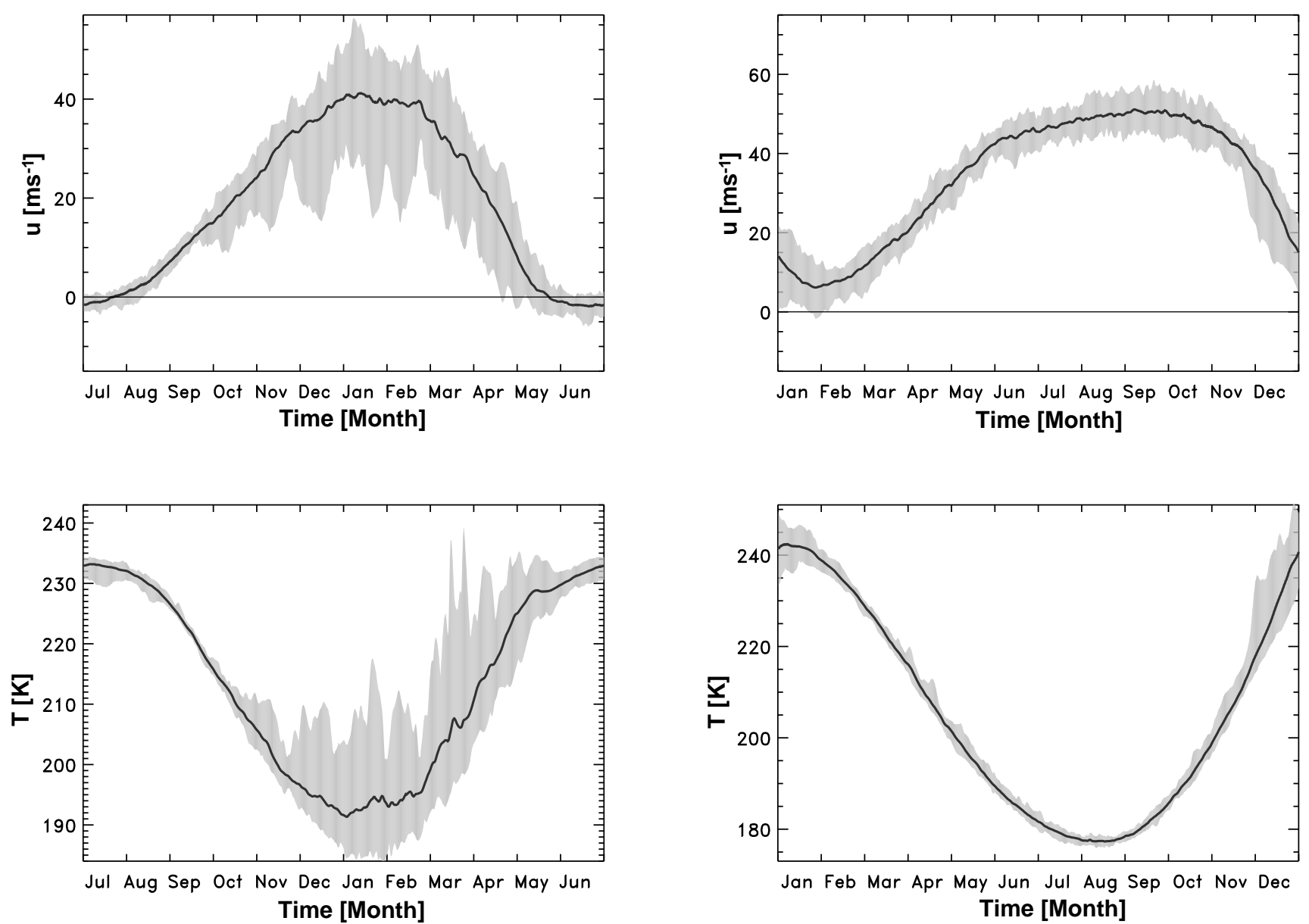

Fig. 16. Modeled zonal mean zonal wind at $60^{\circ} \mathrm{N}, 30 \mathrm{hPa}$ (upper left panel), at $60^{\circ} \mathrm{S}, 30 \mathrm{hPa}$ (upper right panel), and zonal mean temperature at $80^{\circ} \mathrm{N}, 30 \mathrm{hPa}$ (lower left panel), and $80^{\circ} \mathrm{S}, 30 \mathrm{hPa}$ (lower right panel) from a sensitivity simulation applying the ECHAM4/CHEM model in standard L19 vertical resolution. Model data are averaged over 20 simulated years. Shaded areas indicate the interannual variability (minimum to maximum).

substantially. Therefore, in the course of the $21^{\text {st }}$ century, bromine is expected to become relatively more important for ozone destruction. Since the current investigation focuses on recent atmospheric conditions, we do not expect that including bromine chemistry would significantly change the main conclusions.

\section{Conclusions}

The E39/C model has been developed as an interactively coupled climate-chemistry model suitable to perform long-term simulations of the global climate variability and change. This coupling constitutes a large conceptional progress compared to previously published AGCMs, in which climatological means or trends of short-lived radiatively active gases like ozone were prescribed (Bengtsson et al., 1999). In the current paper, we have discussed results of a control simulation representative for recent (1990) atmospheric conditions. From the comparison with numerous observational data, we conclude that the model offers a reasonable representation of the dynamics and chemistry of the global troposphere and lower stratosphere.

The modeled lower stratosphere dynamics in the northern hemisphere show good agreement with observations. The contrast between northern and southern hemisphere variability in polar stratosphere vortex dynamics is realistically simulated. Observed conditions in the northern hemisphere, i.e. temperature and winds, are reproduced well, both in terms of climatological mean states of the stratosphere and their interannual variability. However, southern hemisphere polar vortex dynamics offers some systematic deficiencies, which must be considered with respect to their influence on antarctic ozone chemistry and the simulation of the ozone hole in the model. Simulated total ozone is generally in agreement with climatological observations based on both satellites and ozone sonde data. Particularly, the seasonal variability of total ozone is well reproduced in all geographical regions, including both the Arctic and Antarctica. Vertical ozone profiles are in general agreement with observations in the 
tropics. At mid- and high latitudes, however, the model calculates somewhat too high $\mathrm{O}_{3}$ concentrations in the lower stratosphere and too low $\mathrm{O}_{3}$ concentrations in the tropopause region. The disturbed ozone hole profiles appear to reveal the model's limitations with respect to its upper boundary conditions. In the southern polar winter hemisphere the descent of air into the lower most stratosphere throughout the winter is underestimated.

The E39/C model is able to reasonably simulate the observed inter-hemispheric differences in activated chlorine. The observed asymmetry in chlorine deactivation is also reproduced. Due to the inclusion of the methane oxidation and its feedback on $\mathrm{H}_{2} \mathrm{O}$, the reproduction of the meridional gradient of stratospheric water vapour mixing ratios is clearly improved with respect to earlier ECHAM versions. Water vapour mixing ratios are slightly underestimated near the tropical tropopause and somewhat overestimated in the lower stratosphere. In the tropics the ascent of air seems to be reduced, probably due to the model's top which is centered at $10 \mathrm{hPa}$.

Further investigations and more model simulations are necessary to better understand the reasons for the improved dynamic behaviour of the model relative to former model versions, as well as the reasons for remaining deficiencies. Planned future model improvements include the incorporation of bromine chemistry. Altogether, we summarize that the present model version constitutes an appropriate tool to investigate relevant scientific and social questions, for instance, the combined direct and indirect effects of anthropogenic trace gas emissions, and the simultaneous effect of changing atmospheric chlorine loading and changing climate. We intend to simulate the evolution of the atmosphere during recent decades using E39/C, focusing on the dependence of the ozone layer development from changing chemical and climatic conditions. If these simulations show realistic results, the model may also be applied to simulate scenarios of a possible future evolution of the ozone layer during the $21^{\text {st }}$ century.

Acknowledgement. We thank V. E. Fioletov, who kindly provided the data of his ozone climatology. E. Roeckner and M. Esch are kindly acknowledged for providing sea surface temperature data from their coupled ocean-atmosphere model. We thank the HALOE science team for providing their observational data. Our thanks also go to P. Fortuin for providing the data of his ozone climatology. This study was partly funded by the German Bundesministerium für Bildung und Forschung (BMBF) as part of the Ozonforschungsprogramm and by the European Commission as part of the projects AEROCHEM, and AEROCHEM2. We also thank the staff of debis, Oberpfaffenhofen, Germany, for support in using computer facilities.

Topical Editor D. Murtagh thanks J. Austin and P. Siegmund for their help in evaluating this paper.

\section{References}

Austin, J. and Butchart, N., The influence of climate change and the timing of stratospheric warmings on Arctic ozone depletion, J.
Geophys. Res., 99(D), 1127-1145, 1994.

Austin, J., Knight, J., and Butchart, N., Three-dimensional chemical model simulations of the ozone layer: 1979-2015, Quart. J. Roy. Meteorol. Soc., 126, 1533-1556, 2000.

Bengtsson, L., Roeckner, E., and Stendel, M., Why is the global warming proceeding much slower than expected?, J. Geophys. Res., 104, 3865-3876, 1999.

Benkovitz, C. M., Scholtz, M. T., Pacyna, J., Tarrason, L., Dignon, J., Voldner, E. C., Spiro, P. A., Logan, J. A., and Graedel, T. E., Global gridded inventories of anthropogenic emissions of sulfur and nitrogen, J. Geophys. Res., 101(D), 29239-29253, 1996.

Bojkov, R. D., Hudson, R., Bishop, L., Fioletov, V. E., Russell III., J. M., Stolarski, R., Uchino, O., and Zeferos, C., Ozone variability and trends, in Scientific assessment of ozone depletion: 1998 , WMO global ozone research and monitoring project, Report No. 44, ISBN 92-807-1722-7, 1999.

Brinkop, S. and Roeckner, E., Sensitivity of a general circulation model to parameterizations of cloud-turbulance interactions in the atmospheric boundary layer, Tellus, 47A, 197-220, 1995.

Brinkop, S. and Sausen, R., A modified mass-flux scheme for convection which maintains positive tracer concentrations, Beitr. Phys. Atmosph., 70, 245-248, 1997.

Brühl, C. and Crutzen, P. J., MPIC two-dimensional model, NASA Ref. Publ. 1292, 103-104, 1993.

Chipperfield, M. P., Multiannual simulations with a threedimensional chemical transport model, J. Geophys. Res., 104(D), 1781-1805, 1999.

Chipperfield, M. P., Lee, A. M., and Pyle, J. A., Model calculations of ozone depletion in the Arctic polar vortex for 1991/92 to 1994/95, Geophys. Res. Lett., 23, 559-562, 1996.

Chipperfield, M. P. and Pyle, J., Model sensitivity studies of Arctic ozone depletion, J. Geophys. Res., 103(D), 28389-28403, 1998.

Dameris, M. and Ebel, A., The quasi-biennial oscillation and major stratospheric warmings: A three-dimensional model study, Ann. Geophys., 8, 79-86, 1990.

Dameris, M., Grewe, V., Hein, R., Schnadt, C., Brühl, C., and Steil, B., Assessment of the future development of the ozone layer, Geophys. Res. Lett., 25, 3579-3582, 1998a.

Dameris, M., Grewe, V., Köhler, I., Sausen, R., Brühl, C., Grooß, J.-U., and Steil, B., Impact of aircraft $\mathrm{NO}_{\mathrm{x}}$ emissions on tropospheric and stratospheric ozone. Part II: 3-D model results, Atmos. Environ., 32, 3185-3199, 1998b.

Danilin, M. Y., Sze, N.-D., Ko, M. K. W., Rodriguez, J. M., and Prather, M. J., Bromine-chlorine coupling in the antarctic ozone hole, Geophys. Res. Lett., 23, 153-156, 1996.

DeMore, W. B., Sander, S. P., Golden, D. M., Hampson, R. F., Kurylo, M.J., Howard, C. J., Ravishankara, A. R., Kolb, C. E., and Molina, M. J., Chemical kinetics and photochemical data for use in stratospheric modeling - Evaluation number 11, JPL Publ. 94-26, 1994.

Dentener, F. and Crutzen, P. J., Reaction of $\mathrm{N}_{2} \mathrm{O}_{5}$ on tropospheric aerosols: Impact on the global distributions of $\mathrm{NO}_{\mathrm{x}}, \mathrm{O}_{3}$, and $\mathrm{OH}$, J. Geophys. Res., 98(D), 7149-7163, 1993.

Douglass, A. R., Schoeberl, M. R., Stolarski, R. S., Waters, J. W., Russell, J. M., Roche, A. E., and Massie, S. T., Interhemispheric differences in springtime production of $\mathrm{HCl}$ and $\mathrm{ClONO}_{2}$ in the polar vortices, J. Geophys. Res., 100(D), 13967-13978, 1995.

Fouquart, Y. and Bonnel, B., Computations of solar heating of the Earth's atmosphere: A new parameterization, Beitr. Phys. Atmosph., 53, 35-62, 1980.

Fortuin, J. P. F. and Kelder, H., An ozone climatology based on ozonesonde and satellite measurements, J. Geophys. Res., 
103(D), 31709-31734, 1998.

Franzblau, E. and Popp, C. J., Nitrogen oxides produced from lightning, J. Geophys. Res., 94(D), 11089-11104, 1989.

Gates, W. L., AMIP: The atmosphere model intercomparison project, Bull. Amer. Meteor. Soc., 73, 1962-1970, 1992.

Gates, W. L., et al., An overview of the results of the atmospheric model intercomparison project (AMIP I), Bull. Amer. Meteor. Soc., 80, 29-52, 1999.

Grewe, V. and Dameris, M., Heterogenous PSC ozone loss during an ozone mini-hole, Geophys. Res. Lett., 24, 2503-2506, 1997.

Grewe, V., Dameris, M., Sausen, R., and Steil, B., Impact of stratospheric dynamics and chemistry on northern hemisphere midlatitude ozone loss, J. Geophys. Res., 103(D), 25417-25433, 1998.

Grewe, V., Dameris, M., Hein, R., Köhler, I., and Sausen, R., Impact of future subsonic aircraft $\mathrm{NO}_{\mathrm{x}}$ emissions on the atmospheric composition, Geophys. Res. Lett., 26, 47-50, 1999.

Grooß, J.-U., Modelling of stratospheric chemistry based on HALOE/UARS satellite data, Ph.D. thesis, Fachbereich Physik der Universität Mainz, Mainz, Germany, 1996.

Hansen, G. and Chipperfield, M. P., Ozone depletion at the edge of the arctic polar vortex 1996/1997, J. Geophys. Res., 104(D), 1837-1845, 1999.

Hanson, D. R. and Mauersberger, K., Laboratory studies of nitric acid trihydrate: Implications for the south polar stratosphere, Geophys. Res. Lett., 15, 855-858, 1988.

Hao, W. M., Liu, M.-H., and Crutzen, P. J., Estimates of annual and regional releases of $\mathrm{CO}_{2}$ and other trace gases to the atmosphere from fires in the tropics, based on the FAO statistics for the period 1975-1980, in Fire in the Tropical Biota, Ecological Studies, vol. 84, edited by J. G. Goldammer, pp. 440-462, Springer-Verlag, New York, 1990.

Harries, J. E., Russell III, J. M., Tuck, A. F., Gordley, L. L., Purcell, P., Stone, K., Bevilacqua, R. M., Gunson, M., Nedoluha, G., and Traub, W. A., Validation of measurements of water vapor from the Halogen Occultation Experiment (HALOE), J. Geophys. Res., 101(D), 10205-10216, 1996.

Hein, R., Crutzen, P. J., and Heimann, M., An inverse modeling approach to investigate the global atmospheric methane cycle, Global Biogeochem. Cycles, 11, 43-76, 1997.

Holton, J. R., and Tan, H.-C., The quasi-biennial oscillation in the northern hemisphere lower stratosphere, J. Meteorol. Soc. Japan, 60, 140-147, 1982.

Huntrieser, H., Schlager, H., Feigl, C., and Höller, H., The transport and production of $\mathrm{NO}_{\mathrm{x}}$ in electrified thunderstorms: Survey of previous studies and new observations at midlatitudes, J. Geophys. Res., 103(D), 28247-28264, 1998.

IPCC, (Intergovernmental Panel on Climate Change), Climate change 1995, The science of climate change, Eds. J.T. Houghton et al., Cambridge University Press, Cambridge, U.K., 1996.

Komhyr, W. D., Oltmans, S. J., Franchois, P. R., Evans, W. F. J., and Matthews, W. A., The latitudinal distribution of ozone to 35 $\mathrm{km}$ altitude from EEC ozonesonde observations, 1985-1987, in Ozone in the atmosphere, Proceedings of the Quadrennial Ozone Symposium 1988 and tropospheric ozone workshop, edited by R. D. Bojkov and P. Fabian, Deepak Publishing, Hampton, VA, 147-150, 1989.

Land, C., Ponater, M., Sausen, R., and Roeckner, E., The ECHAM4.L39(DLR) atmosphere GCM - Technical description and model climatology, Report No. 1991-31, DLR Oberpfaffenhofen, Weßling, Germany, ISSN 1434-8454, 1999.

Landgraf, J. and Crutzen, P. J., An efficient method for online calculations of photolysis and heating rates, J. Atmos. Sci., 55,
863-878, 1998.

Lee, D. S., Köhler, I., Grobler, E., Rohrer, P. J., Sausen, R., Gallardo-Klenner, P. J., Olivier, J. G. J., Dentener, F. J., and Bouwman, A. F., Estimations of global $\mathrm{NO}_{\mathrm{x}}$ emissions and their uncertainties, Atmos. Environ., 31, 1735-1749, 1997.

Logan, J. A., Nitrogen oxides in the troposphere: global and regional budgets, J. Geophys. Res., 99(D), 25533-25585, 1983.

Louis, J.-F., A parametric model of vertical eddy fluxes in the atmosphere, Boundary-Layer Meteorol., 17, 187-202, 1979.

Manzini, E. and McFarlane, N. A., The effect of varying the source spectrum of a gravity wave parameterization in a middle atmosphere general circulation model, J. Geophys. Res., 103(D), 31523-31539, 1998.

Miller, M. J., Palmer, T. N., and Swinbank, R., Parameterization and influence of sub-grid scale orography in general circulation and numerical weather prediction models, Meteorol. Atmos. Phys., 40, 84-109, 1989.

Mitchell, J. F. B., Manabe, S., Meleshko, V., and Tokioka, T., Equilibrium Cliamte Change, in Climate Change, The IPCC Scientific Assessment, edited by J.T. Houghton et al., 131-172, Cambridge University Press, 1990.

Morcrette, J. J., Radiation and cloud radiative properties in the European Centre for Medium Range Weather Forecasts forecasting system, J. Geophys. Res., 96(D), 9121-9132, 1991.

Müller, R., Die Chemie des Ozons in der polaren Stratosphäre, $\mathrm{Ph} . \mathrm{D}$. thesis, Fachbereich Geowissenschaften der Freien Universität Berlin, Berlin, Germany, 1994.

Müller, R., Crutzen, P. J., Grooß, J.-U., Brühl, C., Russell III, J. M., and Tuck, A. F., Chlorine activation and ozone depletion in the arctic vortex: Observations by the Halogen Occultation Experiment on the Upper Atmosphere Research Satellite, J. Geophys. Res., 101(D), 12531-12554, 1996.

Müller, R., Crutzen, P. J., Grooß, J.-U., Brühl, C., Russell III, J. M., Gernandt, H., McKenna, D. S., and Tuck, A. F., Severe chemical ozone loss in the arctic during the winter of 1995/96, Nature, 389, 709-712, 1997a.

Müller, R., Grooß, J.-U., McKenna, D. S., Crutzen, P.J., Brühl, C., Russell III, J. M., and Tuck, A. F., HALOE observations of the vertical structure of chemical ozone depletion in the arctic vortex during winter and early spring 1996-1997, Geophys. Res. Lett., 24, 2717-2720, 1997b.

Naujokat, B., Petzoldt, K., Labitzke, K., Lenschow, R., Rajewski, B., Wiesner, M., and Wohlfart, R.-C., Report on the winter 1991/92: the winter of the European arctic stratospheric ozone experiment, in Solar-Terrestrial Energy Program: Collection of reports on the stratospheric circulation during the winter 1974/75-1991/92, edited by B. Naujokat and K. Labitzke, 279_ 301, 1993.

Oltmans, S. J., Komhyr, W. D., Franchois, P. R., and Matthews, W.A., Tropospheric Ozone: variations from surface and ECC ozonesonde observations, in Ozone in the atmosphere, Proceedings of the Quadrennial Ozone Symposium 1988 and tropospheric ozone workshop, edited by R. D. Bojkov and P. Fabian, Deepak Publishing, Hampton, VA, 539-543, 1989.

Pawson, S. et al., The GCM-reality intercomparison project for SPARC (GRIPS): Scientific issues and initial results, Bull. Amer Meteor. Soc., 81(4), 781-796, 2000.

Price, C. and Rind, D., A simple lightning parameterization for calculating global lightning distributions, J. Geophys. Res., 97(D), 9919-9933, 1992.

Price, C. and Rind, D., Modeling global lightning distributions in a general circulation model, Mon. Wea. Rev., 122, 1930-1937, 
1994.

Pumphrey, H. C., Validation of a new prototype water vapor retrieval for the UARS Microwave Limb Sounder, J. Geophys. Res., 104(D), 9399-9412, 1999.

Randel, W. J., Global atmospheric circulation statistics, 1000-1 mb, NCAR Tech. Note, TN-366+STR, 1992.

Rasch, P. J. and Lawrence, M. G., Recent development in transport models at NCAR, in MPI workshop on conservative transport schemes 2-3 June 1997, edited by B. Machenhauer, Max-PlanckInstitut für Meteorologie, Report No. 265, Hamburg, Germany, 1998.

Rex, M. et al., In situ measurements of stratospheric ozone depletion rates in the arctic winter 1991/92: A Lagrangian approach, J. Geophys. Res., 103(D), 5843-5853, 1998.

Rex, M. et al., Chemical ozone loss in the arctic winter 1994/95 as determined by the MATCH technique, J. Atmos. Chem., 32, $35-59,1999$.

Rind, D., Suozzo, R., and Balachandran, N. K., The GISS Global Climate Middle Atmosphere Model. Part 2: model variability due to interactions between planetary waves, the mean circulation, and gravity wave drag, J. Atmos. Sci., 45, 371-386, 1988.

Rind, D., Shindell, D. T., Lonergan, P., and Balachandran, N. K., Climate change and the middle atmosphere. Part III: The doubled $\mathrm{CO}_{2}$ climate revisited, J. Climate, 11, 876-894, 1998.

Roeckner, E., Parameterization of cloud radiative properties in the ECHAM4 model, in Cloud microphysics parameterizations in global circulation models, Proceedings of the WCRP Workshop, WCRP Report No. 93, WMO/TD-No. 713, 105-116, 1995.

Roeckner, E., Arpe, K., Bengtsson, L., Brinkop, S., Dümenil, L., Esch, M., Kirk, E., Lunkeit, F., Ponater, M., Rockel, B., Sausen, R., Schlese, U., Schubert, S., and Windelband, M., Simulation of the present-day climate with the ECHAM model: Impact of model physics and resolution, Max-Planck-Institut für Meteorologie, Report No. 93, Hamburg, Germany, 1992.

Roeckner, E., Arpe, K., Bengtsson, L., Christoph, M., Claussen, M., Dümenil, L., Esch, M., Giorgetta, M., Schlese, U., and Schulzweida, U., The atmospheric general circulation model ECHAM4: Model description and simulation of present-day climate, Report No. 218, Max-Planck-Institut für Meteorologie, Hamburg, Germany, ISSN 0937-1060, 1996.

Roeckner, E., Bengtsson, L., Feichter, J., Leliefeld, J., and Rodhe, H., Transient climate change simulations with a coupled atmosphere-ocean GCM including the tropospheric sulfur cycle, J. Climate, 12, 3003-3032, 1999.

Roelofs, G. J. and Lelieveld, J., Distribution and budget of $\mathrm{O}_{3}$ in the troposphere calculated with a chemistry general circulation model, J. Geophys. Res., 100(D), 20983-20998, 1995.

Rosenfield, J. E., Newman, P. A., and Schoeberl, M. R., Computations of diabatic descent in the stratospheric polar vortex, J. Geophys. Res., 99(D), 16677-16689, 1994.

Russell III, J. M., Gordley, L. L., Park, J. H., Drayson, S. R., Hesketh, W. D., Cicerone, R. J., Tuck, A. F., Frederick, J. E., Harries, J. E., and Crutzen, P. J., The Halogen Occultation Experiment, J. Geophys. Res., 98(D), 10777-10797, 1993.

Santer, B.D., Taylor, K. E., Wigley, T., Johns, T. C., Jones, P. D., Karoly, D. J., Mitchell, J. F. B., Oort, A. H., Penner, J. E.,
Rameswamy, V., Schwarzkopf, M. D., Stouffer, R. J., and Tett, S., A search for human influences on the thermal structure of the atmosphere, Nature, 382, 39-46, 1996.

Santer, B. D., Hnilo, J. J., Wigley, T. M. L., Boyle, J. S., Doutriaux, C., Fiorino, M., Parker, D. E., and Taylor, K. E., Uncertainties in observationally based estimates of temperature changes in the free atmosphere, J. Geophys. Res., 104, 6305-6333, 1999.

Sausen, R., Voss, R., and Ponater, M., Orographic forcing in ECHAM, Beitr. Phys. Atmosph., 66, 239-252, 1993.

Schmitt, A. and Brunner, B., Emissions from aviation and their development over time, in Pollutants from air traffic - results of atmospheric research 1992-1997, DLR-Mitt. 97-04, edited by U. Schumann et al., 37-52, DLR Köln, Germany, 1997.

Schoeberl, M. R., Lait, L. R., Newman, P. A., and Rosenfield, J. E., The structure of the polar vortex, J. Geophys. Res., 97(D), 7859-7882, 1992.

Shindell, D. T., Climate change and the middle atmosphere. Part IV: Ozone response to doubled $\mathrm{CO}_{2}$, J. Climate, 11, 895-918, 1998a.

Shindell, D. T., Rind, D., and Lonergan, P., Increased polar stratospheric ozone losses and delayed eventual recovery owing to increasing greenhouse-gas concentrations, Nature, 392, 589-592, 1998b.

Simmons, A. J., Untch, A., Jacob, C., Kallberg, P., and Unden, P., Stratospheric water vapour and tropical tropopause temperatures in ECMWF analyses and multi-year simulations, Quart. J. Roy. Meteorol. Soc., 125, 353-386, 1999.

Sonntag, D., Advancements in the field of hygrometry, Meteor. Z., 3, 51-66, 1994.

Steil, B., Dameris, M., Brühl, C., Crutzen, P. J., Grewe, V., Ponater, M., and Sausen, R., Development of a chemistry module for GCMs: first results of a multiannual integration, Ann. Geophysicae, 16, 205-228, 1998.

Tiedtke, M., A comprehensive mass flux scheme for cumulus parameterization in large-scale models, Mon. Wea. Rev., 117, 1779-1800, 1989.

Timmreck, C., Graf, H.-F., and Feichter, J., Simulation of Mt. Pinatubo volcanic aerosol with the Hamburg climate model ECHAM4, Theor. Appl. Climatol., 62, 85-108, 1999.

Tuck, A. F., Synoptic and chemical evolution of the Antarctic vortex in late winter and early spring, 1987, J. Geophys. Res., 94(D), 11687-11737, 1989.

van Dorland, R., Dentener, F. J., and Lelieveld, J., Radiative forcing due to tropospheric ozone and sulfate aerosols, J. Geophys. Res., 102(D), 28079-28100, 1997.

von der Gathen, P. et al., Observational evidence for chemical ozone depletion over the Arctic in winter 1991-92, Nature, 375, 131134, 1995.

Williamson, D. L. and Rasch, P. J., Water vapor transport in the NCAR CCM2, Tellus, 46A, 34-51, 1994.

WMO, Scientific assessment of ozone depletion: 1998, Global Ozone Research and Monitoring Project, Report No. 44, World Meteorological Organisation, Geneva, 1999.

Yienger, J. J., and Levy II, H., Empirical model of global soilbiogenic $\mathrm{NO}_{\mathrm{x}}$ emissions, J. Geophys. Res., 100(D), 1144711464, 1995 . 